\title{
TEMPLOS KOGI
}

Introducción al simbolismo y a la astronomía del espacio sagrado. 


\section{X 2019M37}

Bh s y omablodmia ts nobowboryt

obstgse oissqea leb simonoved

NOTA

Para transcribir el idioma Kogi se han usado los siguientes signos:

c como ch española en 'hecho'

$\checkmark$ como sh inglesa en 'ship'

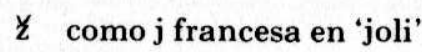

$x$ como $j$ española en 'caja'
Entre los actuales indios de la Sierra Nevada de Santa Marta la institución del templo, como centro y punto focal de la vida religiosa, continúa siendo de considerable importancia. En el presente artículo tratinua siendo de conses templos kogi, con el propósito de introducir un tetaré en detalle de los templos kogi, con el pro intensivo, a saber el signima que aún no ha sido objeto de un estudio intensivo, a saber el significado y algunas de las funciones del templo en aquellas sociedades indigenas colombianas que constituyeron el nivel de los cacicazgos subandinos y aún el de los estados incipientes basados en federaciones de aldeas. En la época de la Conquista estos grupos, representados por los Tairona, Muiska, Sinú y muchas tribus de la Cordillera Central, expresaban na, Muiskas cuales un nivel cultural caracterizado por varias institudote-templo-ídolo. A peocupaba una posición central el complejo sacerdote-templo-ídolo. A pe a veces abarcaban apenas algunos valles contiguos, los cacicazgos -ina veces abarcaban apenas algunos aqui a los estados incipientes - se basaban en una sociedad estratificada, organizada políticamente bajo jefes locales y el cacique asumía ocasionalmente las funciones de un jefe guerrero. En efecto, guerras mía ocasion crónicas eran otra característica de estos grupos intertribales más o menos cronicas y con la organización y ellas se relacionaban con los conceptos religiosos y con la organización social. La base económica de estas sociedades eran la agricultura y el comercio. De todas maneras, los cacicazgos constituyeron un fenómeno imcomercio. De desarrollo cultural de los grupos indígenas colombianos portante en sus asociaciones, desempeñaban un papel fundamental en la organización, cohesión y orientación peñaban un papel fundames es urgente ideológica de estas sociedades. El estudio de estos fenómenos no sólo por razones teóricas, sino por ciertas con no solo pencionado óbviamente no debe limitarLa investigacion sore cronistas, o a especulase a la recopilación de noticias contenidas en de ciones de carácter arqueológico, sino es necesario hacer amplo uso de datos etnológicos modernos. En Colombia existen todavía varias tribus datos etnologico entre las cuales ha sobren en la actualidad, podrá contudio de esta institución, tal como aparece en la actualidá, podrá contribuir a orientaciones importantes para el análisis histórico de dichos desarrollos culturales. Pero también es obvio que estos grupos indígenas desarrollos culturales. Pero tambio hacia la llamada 'inteactuales se encuentran en un proceso de cambio hacia la llamada de los gración' que muy pronto hará desaparecer los últimos vestigios de los principios tradicionales que rigen, o han regido, la institución del templo. principios tradicionales que rigen, o han regido, la por cierto no son más

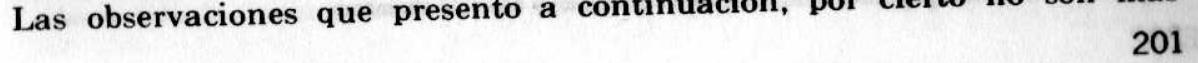


que un resumen muy conciso de un extenso corpus de datos que he podido obtener entre los Kogi, pero espero que indicarán una dirección de futuros estudios en otros grupos indígenas del país ${ }^{1}$.

\section{TIPOS DE TEMPLOS}

Entre los Kogi, los templos (nuhué) $^{2}$ son amplias construcciones de madera que sirven de lugares de reunión a los hombres, por lo general en presencia de un sacerdote $(m a ́ m a)^{3}$. No constituyen exclusivamente lugares de culto, pues en ellos se discuten también asuntos administrativos y de orden público, pero siempre conservan su carácter sagrado que se expresa en muchos detalles formales de contenidos simbólicos y de conducta. Un templo representa un espacio sagrado, claramente delimitado en todas sus dimensiones y, por consiguiente, se le considera ser un lugar con características muy propias y diferentes a las de otras dimensiones espaciales.

En muy resumidas palabras, un templo kogi se puede describir como una construcción circular, similar a una casa de vivienda pero bastante más grande, provisto de un techo alto cónico y de dos puertas bajas opuestas. El diámetro puede ser de unos 7 a 9 metros, lo mismo que la altura.

Hay esencialmente cuatro tipos de templos. El primero consiste de los templos comunes de aldea. En cada poblado kogi, sea un caserío de media docena de viviendas o sea una población grande de un centenar de casas, se encuentra por lo menos un templo que sirve de lugar de reunión. Con frecuencia ocupa un lugar central dentro de la aldea, agrupándose las casas de vivienda alrededor de él, pero no necesariamente ocupa un lugar prominente y a veces el templo está situado en una zona marginal, entre las últimas casas del poblado. En su modo de construcción estos templos de aldea muestran siempre una clara distinción entre techo y pared, es decir, entre un corto cilindro y un alto cono superpuesto. La pared consiste de gruesas cañas, abiertas y entretejidas de una

1 En mis investigaciones etnológicas entre los Kogi han transcurrido más de 30 años, durante los cuales he regresado periódicamente a la Sierra Nevada. Como siempre, debo mis agradecimiendurante los cuales he regresado periódicamente a la Siera Nevada. Como siempre, debo mis agradecimien.

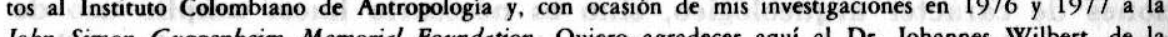
John Simon Guggenheim Memorial Foundation. Quiero agradecer aqui al Dr. Johannes Wilbert, de la Universidad de California, Los Angeles, por los estímulos intelectuales que me ha proporcionado su vasta experiencia. Agradezco al Dr. Clemente Garabito, director del Planetario Distrital de Bogotá, los datos en que se basa la Figura 1, así como la revisión del texto referente a problemas astronómicos. Para un panorama más amplio de la cultura kogi, refiero al lector a mis publicaciones previas (véase Bibliografia).

2 La expresión vernacular española 'cansamaría' para designar estas construcciones es de origen misional colonial y sigue en uso entre la población mestiza.

3 El término máma se relaciona con báma/abuelo; la mujer de un máma se llama saka/abuela, y los dos términos se usan para designar al Sol y a la Luna. Por su formación, tradición y funciones religiosas, los mámas kogi pueden designarse como sacerdotes y no como chamanes. manera que llegan a formar una especie de estera muy espesa y rígida mientras que el techo consiste de una armazón cónica cubierta de paja ${ }^{4}$.

El segundo tipo es propio de los centros ceremoniales que se encuentran en las cercanías de los principales poblados, ante todo en la vertiente norte de la Sierra Nevada. Me refiero aquí a lugares tales com Noavaka arriba de Hukuméiź; Séižaa, al pie de la población de San Mi(on Miguel; Guimelake, cerca de San Francisguel; Sekarino, arriba de San Miguel; Guimelake, cerca de San Francisco; Cerúa, Surlibaka y Mamarongo, y algunos otros más. Estos centro ceremoniales consisten de algunas pocas casas de vivienda construídas al lado o alrededor de uno o más templos, ocupadas por los sacerdotes y sus familias, así como por algunos hombres que - temporal o permanentemente- desempeñan algún cargo especial al lado del sacerdote. En sus detate- desemen similares a los de las aldeas lles arquitectónicos estos templos son muy similares a los de las aldeas pero se distinguen de éstos por sus mayores proporciones y su mejor mantenimiento. Un templo visitado a diario por uno o varios sacerdotes se tenimiento. Un templo visitado a diojor estado de limpieza y reparación encuentra naturalmente en un mejor estado de limpieza y reparación que uno donde sólo ocasionalmente se reunen algunos hombres que van de paso, y donde sólo de vez en cuando entra un máma. A veces lo templos de estos centros ceremoniales que se pueden designar como 'me templos de estos centros co modo que representa una forma tradiciona nores', se construyen de un modo que representa una forma tradicional más antigua; en lugar de tratarse de dos componentes esenciales -pared y techo- este último se prolonga hasta et suelo, de modo que la cons trucción adquiere la forma de una colmena de techo puntiagudo.

El tercer tipo de templo se encuentra casi sólo en los centros ceremoniales mayores, como por ejemplo en Takina o en Makotama, am biguel. Tienen siempre forma de colbos listinguen además en mena, con ex templos públisu exterior por sus elaborados apices. cos asequibles a todos los hombres kogi, sino de verdaderos santuarios coservan objetos de culto y alrededor de los cuales se celebran actos religiosos en determinadas ocasiones.

Un cuarto tipo de templo se distingue no tanto por su forma sino más bien por su uso; se trata de los templos particulares que construyen los sacerdotes. Al llegar a cierta edad, algunos mámas se hacen consyen los sacera ca truir un templo privado, sea un sitio alejado, en las faldas montañosas. Allá el máma pasa largas temporadas; de vez en cuando recibe visitas, pero más bien está retirado de la vida religiosa colectiva y ahora dedicado a la meditación, compartida ocasionalmente con otros hombres ancianos, o a la enseñanza de uno o dos aprendices.

Aunque en cada templo hay varios fogones y un sencillo mobiliario de hamacas, bancas y algunos otros objetos, el carácter sagrado del lu-

Conocí un solo templo cuyo techo estaba cubierto de hojas de palma (Carludovica) .en lugar de Era en San Andrés, en las cabeceras del río Frio, aldea kogi que fue invadida por mestizos en 1948

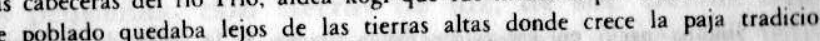
nalmente indicada, el máma de San Andrés dió el permiso de techar el templo con estas hojas. 
gar se manifiesta inmediatamente. No es permitido que se prepare o con suma comida en su interior, ni tampoco que éste se convierta en un mero dormitorio. A las mujeres y a los niños les está del todo prohibida la entrada a un templo, lo mismo como a los borrachos, a personas que estén peleando o hablando en alta voz, o a animales.

Antes de entrar a la descripción de las diversas funciones del tem plo kogi - en diferentes lugares y ocasiones- debo tratar brevemente de las tradiciones que se relacionan con el origen de la institución como espacio sagrado.

\section{ORIGENES MITICOS DEL TEMPLO}

Según los mitos de origen el primer templo fue ideado por los cuatro hijos principales de la Madre Universal, los Señores Sehukúkui, Seižán kua, Aldauhuíka y Kuncavitabuéya ${ }^{5}$. La cosmogonía kogi habla de la creación de nueve mundos escalonados, el uno encima del otro, comparándoles con los nueve meses de gestación humana, detallando sus características y evolución sucesiva. (Figura 1). Cuando se estaba formando el noveno mundo, el más alto, una inmensa ceiba ${ }^{6}$ comenzaba a surgir de mar prístino y alrededor de este eje cósmico los cuatro hermanos divinos construyeron el primer templo y lo llamaron alnáua. Aún no había amanecido y la tierra estaba aún floja y yacía bajo las tinieblas ${ }^{7}$ pero una vez que había nacido el Primer Hombre - llamado Sintána-se hizo la luz y amaneció el primer día de la Creación. Ahora los cuatro Señores comenzaron a secar la tierra y a empujar lejos el mar que la circundaba. Hecho ésto se reunieron en el templo que habían hecho y cantaron pidiendo que la Madre les diera mujeres. La Madre había tenido nueve hijas, cada una de las cuales representaba cierta calidad de tierra de cultivo o sea tierra arenosa, tierra gredosa, o tierra amarilla, pero ahora, al en tregar sucesivamente estas hijas -tierras a los cuatro Señores, éstos pronto se dieron cuenta de que ellas eran estériles o, por lo menos, no prometían ser madres fecundas para poblar este mundo. Así pidieron tierra ne gra, la hija negra de la Madre, la buena tierra de siembra; pero la Madre se negó a entregarla y la guardaba en un gran cuarto obscuro. Mientras que los cuatro Señores se colocaban en las cuatro esquinas del mundo, Sintána, el primer hombre de la Creación, se puso de pie en el cen tro del templo y cantó: "inda-u-o, ahora voy a tener aquí mi templo". La muchacha oyó el canto y quedó subyugada por el atractivo de su voz. Se levantó, pero no se atrevió a salir. Entonces Sintána llamó a su

5 Los nombres de estos personajes míticos están generalmente precedidos por los términos honorificos bate/padre o maku//jefe que, en español, se pueden traducir como 'Seño '.

6 La ceiba se llama ululá o se personifica con el nombre del mítico Máma Zinkala. Fue el primer árbol de la Creación. Según otros datos se trataba de un cedro.

7 Sintána nació en nyi-dulúma/agua-espuma o la 'casa de espuma', un ambiente uterino en el fondo del mar. En algunos textos esta 'casa' se designa como templo. compañero el Viento y le pidió que le ayudara. El Viento busco en todos los rincones hasta que encontró a la muchacha - la tierra negra - y. tomándola por la cintura la llevó donde estaba Sintána. Fue así como se inició la vida humana - representada aquí por la primera pareja - en un templo, el templo que habían construído los cuatro Señores y de donde Sintána salió ahora a poblar el mundo kogi.

En aquellos primeros tiempos todos los Señores y Dueños sobrenaturales construyeron sus propias moradas o templos dentro de los cerros de las montañas. Los cerros, grandes y pequeños, de forma cónica, son to dos templos (nuhuá-xalda) y se agrupan en una gran población que es la Sierra Nevada. En cada una suponen que exista gran número de habitantes, sea la parentela del dueño de un fenómeno natural, o sea de ciertos animales. En la obscuridad de las entrañas de estas inmensas moradas están las personificaciones de los vientos y las enfermedades, de murciélagos, venados o armadillos, de una multitud de seres que viven allí su vida secreta pero a la vez tan parecida a la de los seres humanos. En la cima de estos cerros hay lagunas que son los ápices de estos templos y en las vertientes de las montañas hay cuevas o grietas que son las puertas que conducen al interior de estos templos sobrenaturales.

De ahí en adelante, al paso que se iba poblando el mundo kogi se fundaron los primeros grandes templos de la tribu. Sehukúkui y Mulkuéxe -este último el quinto hijo de la Madre- representando los conceptos de Noche y Día, establecieron el primer templo en Cerua, lugar mítico donde la Madre habia sembrado la 'mata de ahuyama', la cucúrbita original que por el lento crecimiento de sus ramajes bifurcados simbolizaba la expansión demográfica de la tribu. Luego se fundó el templo de Guamáka (o Guimelake?), luego el de Takina, el de Sekaríno (KulCá ka) y por último el de Séǐ̌a. Por cierto, la secuencia de esta enumeración puede variar pues en cada región la gente se aprecia de tener uno de los templos más antiguos. Según la tradición, los cuatro hijos de la Madre fueron así mismo los fundadores y progenitores de los linajes sacerdotales de Takina, Makotáma, KulKáka y Séižua, cuyos mámas actuales aún se dicen descender de aquellos ancestros divinos.

Un fragmento mítico complementa esta etapa de la Creación. La Madre Universal, única poseedora del arte de hilar y tejer, tomó su in menso huso y lo clavó verticalmente en la tierra recién creada. Lo puso en el centro de la Sierra Nevada, atravesó su pico más alto, y dijo: "Esto es kalvasánkua, el poste central del mundo!". Al decir eso desprendió de la punta del huso una hebra de hilo de algodón y, con su extremo. trazó un círculo alrededor del eje vertical, declarando: "Esta será tierra de mis hijos!". Ahora bien: el volante de huso que es plano discoide representa nuestra tierra, la tierra negra, la quinta en la secuencia d las nueve tierras. Hacia arriba siguen cuatro tierras más hasta donde ter mina el hilo enrollado, y continúa luego el eje cósmico hasta el cenit. Estas tierras también son planas y de forma discoidal, pero son progre sivamente más y más pequeñas. Son tierras de luz, de sol, tierras bue nas, aunque no tan fértiles como la nuestra. Hacia abajo siguen asi mi mo cuatro tierras, que también disminuyen en diámetro hasta llegar a 
punto del nadir; son las tierras de la obscuridad, de las tinieblas. Esta estructura cósmica es muy compleja y los Kogi la elaboran en gran detalle en sus mitos y cantos. Lo importante es que ellos conciben el cosmos bajo la forma de dos conos unidos por las bases, imagen que encontraremos en muchos otros contextos. El hilo de algodón envuelto sobre el eje encima del volante forma un cono - dividido en cuatro mundos superiores - mientras que en la parte por debajo del volante conciben otro cono, también dividido en cuatro mundos y que se dicen estar formados por un hilo negro, invisible, enrollado alrededor del eje del huso. Este concepto de inversión, sobre todo en un modelo constituído por dos conos (o dos pirámides), es fundamental en el pensamiento kogi y trataré de él aún más adelante.

He hablado aquí de algunos aspectos cosmogónicos para poder explicar mejor el concepto esencial del templo, a saber, su carácter de construcción cósmica. En efecto, todo templo kogi es, según ellos, una réplica del cosmos y los mámas enseñan a los hombres los fundamentos de la cosmología mostrándoles los detalles arquitectónicos del templo. Debo pues tratar en primer lugar de los principios básicos que rigen la construcción de este edificio.

\section{LA CONSTRUCCION DEL TEMPLO}

Los sacerdotes kogi conocen los fenómenos cíclicos de los solsticios y equinoccios, salvo que, desde su punto de vista geocéntrico, ellos creen que el sol da vueltas alrededor de la tierra. Como punto de partida toman el solsticio vernal ( 21 de junio), que es el comienzo del año kogi; ellos han observado que en este día el sol ha llegado al extremo de su marcha hacia el norte y que, de ahí en adelante, empieza a devolverse hacia el sur. El día del solsticio de verano el sol sale por el ENE y se pone por el ONO, pero luego sigue devolviéndose hacia la Sierra Nevada donde llega el 21 de diciembre, fecha del otro solsticio, después de haber pasado por la línea equinoccial el día 21 de septiembre. De regreso hacia el mar, atraviesa nuevamente la línea equinoccial el día 21 de marzo y continúa luego su camino hacia el solsticio vernal. Los puntos de salida y puesta del sol en los días de solsticios, son los cuatro puntos cardinales del universo kogi, son las llamadas "esquinas del mundo", cada una bajo la protección de uno de los cuatro Señores, hijos de la Madre. Así está en el ENE Sehukúkui, en el ONO Seižánkua, en el ESE Aldauhuíku, y en el OSO KunCavitabuéya. En el punto del centro rige el Señor Mulkuéxe, el quinto hijo de la Madre y el preferido de ella; es él quien ocupa el punto meridional del quincunce.

La gran importancia que los Kogi atribuyen a estas fechas solares se debe a su correlación con las estaciones del año y con las condiciones meteorológicas de cada una de éstas. El solsticio de verano (21 de junio) introduce una estación seca que dura hasta fines de septiembre. El equinoccio del 21 de septiembre marca el comienzo de fuertes lluvias que duran hasta diciembre, y el solsticio del 21 de diciembre indica de nuevo 206 el comienzo de un período de sequía que se extiende hasta, aproximadamente, el equinoccio de primavera, el día 21 de marzo. Los meses de abril, mayo y parte de junio son muy lluviosos y sólo al acercarse de nuevo al solsticio de verano, comienzan a disminuir las lluvias. Para un pueblo agricultor como lo son los Kogi, esta división del año, marcada tan claramente por factores astrales, es de importancia fundamental y no es de sorprenderse que el calendario agrícola esté estrechamente relacionado con el calendario ritual. Los movimientos del sol forman pues uno de los más importantes principios de organización de su existencia.

La construcción de un templo kogi está siempre precedida y acompañada por prácticas de adivinación que se refieren no sólo a la ubicación astronómica más conveniente, sino también a múltiples detalles relacionados con las tradiciones míticas del lugar en el cual se construye éste; con la disposición favorable de espíritus de antepasados y de la naturaleza, y con la finalidad precisa del templo en cuestión. La construcción y consagración de un templo en un centro ceremonial es, desde luego, más demorada y se acompaña de ritos más complejos, que la de un simple templo de aldea.

El primer paso en la construcción consiste en determinar el centro exacto del espacio sagrado. Una vez determinado éste -por adivinación y por consideraciones prácticas - el máma o uno de sus ayudantes colocan allí una corta vara firmemente clavada en el suelo, en cuya base se can allí una corta vara firmemente clavada en el suelo, en cuya base se ha amarrado una cuerda de fique y el mama traza con ella la circunferencia de la construcción proyectada. Esta cuerda (subul mujer del máma y tiene una serie de nudos, a ciertas distancias, que permiten al máma indicar a los constructores las proporciones exactas de las diversas partes del templo. El diámetro de un templo corresponde, por lo general, a la altura máxima de su techo ( 7 a 9 metros) y todas las demás proporciones corresponden a un canon fijo.

La construcción de un templo debe iniciarse en una fecha solar, preferible un 21 de junio, para poder colocar en ese día por lo menos el primero de los cuatro postes principales (múxalda), en el NE o ENE, donde el radio cruza la periferia trazada con la cuerda. Al prolongar el radio hacia el SO se pueden instalar luego el poste opuesto y la ubicación de los postes del NO y SE se deriva luego sin dificultad. Estos puntos, desde luego, no corresponden con toda exactitud a las posiciones solares en los solsticios, que se encuentran más hacia el ENE, ESE, ONO y osO, Cada templo tiene dos puertas situadas en lados opuestos y, casi siempre, orientadas tiene dos puertas situadas en lados opuestos y, casi siempre, orientadas este-oeste; consisten de una especie de estera de cañas verticales entreteji-
das. Una vez trazada la línea equinoccial en el suelo, la delimitación del cuadrángulo cósmico se cumplió y con ésta quedar líneas paralelas que marcan el espacio sagrado. A continuación se colocan a cada lado de las puertas un grueso poste inclinado hacia el centro, y dos cores de postes similares se colocan en el sur de la circunferencia. La estructura elemental es pues la de una pirámide, de base rectangular. Estos ocho postes largos y fuertes son los que soportan la estructura del techo y se clavan en su posición con especial cuidado. El 
círculo de la pared está constituído por un gran número de postes de un mismo grosor, entre los cuales se encuentran entrecalados, otros más fuertes, en forma de horquetas. Estos descansan sobre una base formada por una piedra plana y en los espacios entre una horqueta y la otra, se amarran dos fuertes varas cruzadas que, en su parte baja, también se apoyan en las mismas lajas de piedra.

Sigue luego la construcción de las paredes. Sobre un enrejado de varas horizontales, amarradas desde afuera sobre los postes, se pone ahora la gruesa estera de cañas entretejidas, amarrada a trechos a la base rígida de la pared. En la edificación del alto cono del techo se emplean largas varas que se entretejen con bejucos que, formando un cordón contínuo, van en espiral, en el sentido del reloj, hasta la parte más alta del interior del techo. A la altura de unos 2 metros sobre el nivel del suelo, se proyectan dos pares de varas horizontales (kanmalyi) desde el norte y el sur, hacia el interior del espacio donde se apoyan luego en dos gruesos postes (nugikuí) centrales colocados verticalmente al lado del pasadizo que marca la línea equinoccial. Estos dos postes centrales, cada uno dentro de una mitad del círculo, también ayudan a sostener el techo.

En el interior del gran cono del techo se colocan cuatro andamios en forma de estantes o repisas que se proyectan aproximadamente un metro hacia el interior y que consisten de armazones horizontales escalonados (kanmalyi). Los dos postes centrales sostienen el techo a la altura del tercer estante. El armazón del techo se cubre luego con paja del páramo y llega a formar una cubierta gruesa y muy resistente. Los detalles finales consisten en la postura de las puertas y en la manufactura del ápice. Este último consiste, en la mayoría de los templos de alguna importancia, de una especie de amplio embudo hecho de varas unidas por bejucos, parecido al armazón de un paraguas invertido. $\mathrm{La}$ inclinación del techo es siempre alrededor de $45^{\circ}$.

El mobiliario de un templo se compone, por lo general, de los siguientes elementos. Aproximadamente en la mitad de una línea imaginaria que une el centro del templo con los cuatro postes principales, se encuentran cuatro fogones que consisten cada uno de algunas piedras puestas en un círculo, entre las cuales hay ceniza y leña. Alrededor de estos fogones se han puesto algunos banquitos bajos, tallados de un sólo tronco pesado de madera. A lado y lado del pasadizo central, están dos largas bancas bajas (mankasi) adosadas a los dos postes centrales, también talladas de grandes trozos de madera muy dura. Puesto contra la pared, por lo general al lado izquierdo de la puerta occidental, se halla un telar y, colocado a su lado, se observan a veces un huso, algunas bobinas, unas motas de algodón y tal cual otro objeto utilizado para tejer. Así mismo habrá una u otra olla de cerámica para tostar las hojas de coca. De las varas horizontales, que se extienden hacia el interior del templo, cuelgan a veces ganchos o garabatos tallados de madera, donde los hombres pueden colgar sus mochilas. También puede haber un tambor de membrana, una o dos maracas y algunas pequeñas esteras, rectangulares $\mathbf{u}$ ovaladas, para depositar ofrendas. En los principales templos 208 de los centros ceremoniales se guardan además las máscaras de baile, los grandes trípodes de madera para colocar éstas en ciertas ocasiones, asi como bastones tallados, coronas de plumas y otros objetos rituales.

El interior de un templo kogi es, por lo general, muy limpio y cuidado, por lo menos en comparación con el ambiente polvoso de las casas de vivienda. Los hombres ponen énfasis en tener allí un lugar confortable y amplio. La madera y la paja del interior están ennegrecidos por el humo de los fogones y de noche, cuando éstos se enciendan, la madera brilla y el juego de luces y sombras hace resaltar los detalles de la construcción. A los Kogi no les gustan las cosas nuevas, recién hechas; ellos prefieren objetos viejos -no necesariamente antiguos pero sí usadós (túma), y todo lo que se encuentra dentro de un templo tiene este carácter de usado, en el sentido de haber sido manejado por innumerables manos, de haber sido limpiado, guardado, reparado $y$, en todas las circunstancias, de haber sido tratado con respeto. Los Kogi dicen: "Nuestras cosas son sencillas, pero tienen vida".

\section{EL TEMPLO COMO COSMOS}

El templo kogi se llama nuhué/mundo-casa ${ }^{8}$. Siempre me acordaré de un anciano máma que me estaba enseñando el templo de su aldea y que, puesto de pie en el centro del círculo, levantó los brazos y, con la mirada perdida en la penumbra del espacio, exclamó: "Esto es el mundo! Aquí hay de todo, de todo!".

Esta visión de un "todo" formado por innumerables componentés que constituyen algo coherente e integrado, bien puede considerarse como uno de los grandes logros del pensamiento kogi. Para ellos, la interrelación de las partes - sea a escala macrocósmica o microcósmica- es el modelo de la vida humana, no en un sentido de un mecanicismo automático, sino asignando al individuo gran responsabilidad personal por el funcionamiento del universo y sus componentes. La cosmovisión kogi abarca los fenómenos astrales y meteorológicos, la tierra visible e imaginada, la Sierra Nevada, las montañas individuales de cada región, los templos, las casas, y así, hasta el objeto más pequeño de uso personal, todo colocado dentro de un modelo de forma cónica. Por otro lado, los Kogi siempre operan con un concepto de oposiciones complementarias; cada fenómeno $u$ objeto se cree tener su parte opuesta, invisible y negativa pero esencial, y esta división se establece casi siempre sobre un plano vertical de un 'arriba' y 'abajo', que corresponde a conceptos de luz y obscuridad y, finalmente, del Bien y del Mal. Al tomar como modelo cósmico el huso de hilar, el disco del volante es el que divide las dos partes del cosmos, el iluminado de arriba y el obscuro de abajo, y que estable-

8 También se podria derivar de nyui/sol, es decir 'casa de sol', o de $n u$ /hermana mayor. Por cierto, el sentido de la palabra depende muchas veces del contexto simbólico dentro del cual figura. 
ce así dos mundos opuestos según el modelo bicónico, cada uno forman do una escala de valores. Estos mundos se escalonan desde la luz cenita del sol hasta las tinieblas del nadir, cada uno representando una unidad en su propio derecho, pero pudiendo existir sólo en función de su participación en un todo que es, precisamente, este doble cono cósmico. Por cierto, los pisos del cosmos, es decir las gradas de la pirámide, corresponden - según los Kogi- a etapas del desarrollo de la conciencia humana. (Figura 2).

Las escalas son intercambiables y relativas. En un momento del discurso, en una fase del pensamiento y de la meditación, el cosmos se convierte en un templo, o la Sierra Nevada se convierte en una casa. $O$, también, el sol aparece como un hombre y el hombre -como gigantevive en un cerro cónico y este cerro es un templo en cuyo interior se reunen otros hombres, pero ahora a escala humana. $O$ también, el templo es una mujer; toda la Sierra Nevada es una mujer, es la Madre Universal. A estos cambios de escala corresponden cambios de valores. Se le da la vuelta al modelo bicónico $y$, al instante, lo que antes era el inframundo se ha convertido en el mundo de 'arriba'. La luz del día se convierte en "luz negra" (guxtsé abaxse), en luz invisible. Los mámas kogi manejan contínuamente estas inversiones, y su lenguaje metafórico consiste en vastas categorías de expresiones que son intercambiables según el nivel y la intensión de la discusión. Los Kogi dicen: "Hay dos modos de ver las cosas...", queriendo decir que siempre hay ambivalencias y alternativas y que el objetivo de la existencia humana consiste en encontrar un equilibrio entre la multiplicidad de los fenómenos que rodean al individuo.

Después de haber anticipado aquí estas breves consideraciones sobre un aspecto fundamental del pensamiento kogi, trataré ahora del templo en,función de estos modelos e inversiones, y de los niveles de congruencia en que se expresan estas metáforas. En primer lugar, cada templo kogi se considera ser una réplica del cosmos. Los cuatro postes principales colocados en el noreste, noroeste, sureste y suroeste marcan las esquinas del universo; siendo así, el piso circular de la construcción es una réplica del volante de huso. Las cuatro repisas o estantes que se escalonan de abajo hacia arriba en el interior del techo, representan los mundos superiores del cosmos. Además, cada templo se imagina que continúa bajo tierra en forma inversa; dividido por el plan terrestre el templo se concibe como un doble cono (o doble pirámide, si tenemos en cuenta las cuatro esquinas), arriba tangible y visible a la luz del día, abajo intangible e invisible a la luz del "sol negro" (máma nyúi abaxse) que sólo los mámas pueden percibir. Una línea vertical que pasa por la punta del techo, por el centro del piso y el nadir que - en este caso- es el ápice del techo inverso invisible, constituye el eje cósmico, identificado con la varilla del huso, con la gran ceiba de la Creación, o con el poste central (kalvasánkua) que la Madre puso en el centro de los nevados.

Ya que cada uno de los mundos escalonados tiene sus propias divinidades y espíritus, junto con sus habitantes más o menos monstruosos y su flora y fauna especiales, el interior de un templo sirve a los má210 mas para explicar en cualquier momento a los hombres allí reunidos los principales componentes estructurales del cosmos, añadiendo - según sea l caterín. el caso- la descripción de plo como modelo ilustrativo es de destacada importancia en el proceso de transmisión de la herencia cultural del grupo. No sólo su construcción transmision su mobiliario se convierten en medios de enseñanza que, por estar siempre a la vista de los visitantes, de un modo concreto, adquirieron funciones mnemotécnicas.

Pero cambiemos de nivel de interpretación, es decir, de nivel de congruencia; miremos con los Kogi el templo a una escala más pequeña, más humana.

El dios del Trueno es Kuǐ̌bángui. Con su mujer, el Aguacero y sus hijas, el Granizo y el Arco Iris, vive en cerro alto cerca de la población de San Francisco. Este cerro es su casa, su templo. Ahí vive, medio dormido; pero de vez en cuando grita: "Mujer, levántate iVamos a bailar!". Su voz retumba de las laderas y el eco se oye de un extremo del valle al otro. Gritando al través del ruido de la lluvia, para que su mujer acelere el torbellino de su baile, el Trueno lanza sus rayos, riéndose a carcajadas. Por fin ella se cansa y recoge sus faldas, de viento y de lluvia, para sentarse mientras que su marido, aún gruñendo y rezongando via, para sentarse muišbángui es el protector de los templos kogi y cada templo se dice ser una réplica de su cuerpo; los dos postes centrales son sus piernas; los postes de la periferia y el enrejado que los une son sus sus piernas, los postremos superiores de la costillas: las varas hejucos y varas que rode pared son sus caderas y el gru la parte baja interior del techo, es su cintura; el maderamen del techo son sus hombros y su corazón está arriba, en la parte más alta del cono. Los Kogi se imaginan a Kuišbángui de pie, con la espalda doblada, sosteniendo en sus anchos hombros el peso del techo de sus templos.

Pero esta interpretación se puede igualmente substituir por otra. El templo, según dicen los Kogi, es el cuerpo de la Madre Universal, es su útero. Al entrar a un templo el hombre regresa momentáneamente al utero. Al entrar a un tempés seguro y protegido de todo el universo. a marte alta del techo está suspendido un sencillo objeto que con vispiska)y, al bajarlo por una cuerda, los hombres introducen por los anillos opuestos un jarlo por una cuerda, los hombres introducen por los anillos opuestos un par de husos o bobinas con hilo de algodón. Al alzar de nuevo el objeto $y$ poner al mismo tiempo a girar las bobinas, se tuerce un fuerte hilo del cual luego se trenza un cordón que se cose en los hombros y las lo del cual luego se trenza un cordón quén es el cordón umbilical, es la comunicación que une al individuo con la Madre quien lo nutre y protecostar en intimo ge; y al torcer dijo divinidad. El ápice del techo, el embudo de varas, es el órgano sexual de la Madre. Allí el máma coloca ofrendas en forma de frano simbolizan la fertilización del útero y así se garantiza la nueva vida y la continuidad de las tradiciones. También se colisan de dos cortas varitas puestas en cruz y entretejidas lue- 
go con un bejuco. Estos pequeños artefactos se designan como 'murciélagos' y, a su vez, los interpretan de varios modos, a saber, como un sol como vagina, como una telaraña, o como una alusión a la metáfora kog por la cual la menstruación se compara con la mordedura de un murciélago.

Pero estas interpretaciones del templo son sencillas; siguen otras más complejas que cada hombre debe aprender a manejar, al paso que vaya adquiriendo los conocimientos que le servirán de guía en esta vida.

Cada templo kogi simboliza la estructura política de la tribu, en tanto que sus diversas partes estructurales, junto con sus relaciones, se identifican con determinados cargos administrativos y religiosos. He mencionado que al lado de cada puerta, así como en la parte norte y sur de la periferia circular se hallan gruesos y largos postes inclinados hacia el interior que, en realidad, forman los principales soportes del techo. Pues bien, el poste a la derecha de la puerta oriental se identifica con el máma de Takina, es decir, el jefe religioso principal. Le sigue en importancia el máma de Makotama, jefe civil que se identifica con el poste a la izquierda de la misma puerta. A la derecha de la puerta occidental está representado el máma de Séižua y a la izquierda de ella el máma de Mamarongo. El poste del norte está identificado con el 'Comisario Menor' (aguánarse) de Makotama, mientras que el del sur se identifica con el de Séižua. El centro del banco largo (mankaší) adosado al poste central de la sección sur del templo, se identifica con el cargo de 'Comisario Mayor' (hukúkui) y, frente a él, adosado al poste de la mitad norte, está el puesto del 'Cabo Segundo'. Las varas horizontales (kanmalyi) que unen los postes centrales con el círculo de la pared, se identifican con otros hukúkui, mientras que los horcones (seiváke) representan jefes locales de aldeas, y las varas en cruz (yoguí) que les acompañan, son sus ayudantes. Por otro lado, los postes o horcones llamados seiváke se designan también como "muchachos inocentes", como jóvenes aún no iniciados sexualmente. Ellos representan a aquella categoría importante de adolescentes que se encuentran en una fase de transición; aún no les está permitido masticar coca, pero ya pueden tomar parte en algunas reuniones de los hombres. La parte alta de estos postes tienen forma de horqueta que "sobre el hombro derecho" - como dicen los Kogi- sostienen una viga horizontal. La parte baja se designa como sauli/pene, y cada uno de éstos descansa sobre una piedra llamada seiváke koktúma, descrita como 'hija' del poste más cercano que representa a un hukúkui. La multitud de postes que forman el círculo de la pared son la gente, el pueblo (naši); ellos demarcan el espacio, defienden el centro y, en parte, ayudan a sostener el techo. También a los principales personajes míticos les corresponden determinados espacios para colgar sus hamacas. (Figura 4).

La próxima imagen es considerablemente más compleja. En ella los Kogi ven en el templo un modelo de su organización social, junto con la red de interrelaciones que conectan los diversos segmentos de la sociedad. Ya he mencionado que los cuatro postes principales representan las esquinas del universo y que están bajo la tutela de los cuatro prime212 ros hijos de la Madre, mientras que el punto del centro (muán) está bajo la protección del quinto hijo. Ahora bien, ya que - vistos desde el cen tro- los cuatro fogones del templo yacen en las mismas direcciones, cada uno de ellos queda así mismo bajo la tutela de uno de los Señores principales. De acuerdo con las tradiciones, estos cuatro hijos de la $\mathrm{Ma}$ dre, junto con sus mujeres, dieron origen a los primeros cuatro clanes y aún constituyen el patrón fundamental de las reglas de matrimonio. La sociedad kogi representa un sistema de descendencia doble, es decir, de patri- y matrilinajes en las cuales la descendencia se traza de padre a hijo y de madre a hija. Cada linaje está asociado con cierto animal, sea 'masculino' o 'femenino', según la clasificación kogi. Los animales 'masculinos' son el jaguar, el puma, la lechuza y el marsupial, mientras que los animales designados como 'femeninos' son el venado, el pecarí, la cu lebra y el armadillo. Las reglas matrimoniales piden entonces que el hom se case con una mujer cuyo clan esté asociado con un animal que sea presa natural del animal asociado con el clan del hombre. Por ejemplo. un hombre-jaguar deberá casarse con una mujer-venado, un hombre-puma con una mujer-pecarí, un hombre-lechuza con una mujer-culebra, y un hombre-marsupial con una mujer-armadillo. El cuadro siguiente muestra estas asociaciones entre los cuatro Señores, sus patrilinajes y matrilinaje respectivos y sus direcciones y fogones correspondientes.

Cuadro No. 1

\begin{tabular}{|llllll|}
\hline Señor: & Patrilinaje: & Animal: & Matrilinaje: & Animal: & Dirección: \\
\hline Sehukúkui & hokúkui & lechuza & mitamdú & culebra & noreste \\
Seižánkua & hánkua & puma & huldáke & venado & noroeste \\
Kunčavitabuéya & kurča & marsupial & nugénake & armadillo & suroeste \\
Aldauhuíku & hukuméiži & jaguar & seináke & pecarí & sureste \\
\hline
\end{tabular}

De esta manera, los cuatro fogones son centros y sedes de los fundadores originales, junto con sus descendientes terrestres. Así, cuando los hombres se reunen por la noche en un templo, no pueden sentarse en cualquier parte sino deben ocupar cada uno su puesto al lado del fogón que le corresponde, según el esquema cósmico. (Figura 3 ).

Aparte de estas asociaciones existen muchísimas más. Entre ellas se incluyen patri- y matrilinajes posteriores así como personajes míticos de ambos sexos, designados aquí como hate/padre, haba/madre, due/hermano mayor, y nu/hermana mayor. Las demás asociaciones de cada uno de los cuatro fogones del templo son entonces las siguientes:

Fogón nororiental:

Sehukúkui, el primer hijo de la Madre. Se designa como Dueño de la Noche y Señor de las Sombras; le pertenecen todos los animales negros. Personajes míticos asociados: Los Padres Kassaúgi, Žalyintána, Sankalaména y Gulaména; Padre Du. ginávi, un hijo de la Madre; además, los matrili- 
najes de las huldáke, seináke, námukalye, séi Zaldake, hélbyeldake, senšina y džuíname.

Fogón noroccidental:

Seižánkua, el segundo hijo de la Madre. Seizánkua es el Dueño de la Tierra y de las Plantas, especialmente de los árboles de la selva.y a él le incumbe todo lo referente al mundo vegetal no cultivado por el hombre. Personajes míticos asociados: los Padres DžibundŽža, Zantána, Saci y Sáungelda; los hijos de la Madre, Kašindúkua y Namsíku; Sintána, el primer Hombre; el matrilinaje de las mitamdú y las personificaciones femeninas Saumá, Šivaldungáya y Žangáuli, así como el mítico Máma Singáunguldu.

Fogón suroriental:

Kunčavitabuéya, el tercer hijo de la Madre, designado como Señor del Agua. Están asociados con él: Kuiłbángui, el Señor del Trueno; los personajes míticos Námaku, Saldáui, Nyíueldue, Nurlita y Hibáxa, así como Noánase, un hijo de la Madre, y una Madre mítica llamada Haba Nuvingó. Fuera de los Kurca, los patrilinajes asociados son los doaná-tuxe, nugi-tuxe y saldáka-tuxe, mientras que los matrilinajes son las nugénake, hélbyeldake y séižaldake.

Fogón suroccidental: Aldauhuíku, el cuarto hijo de la Madre, designado como Señor del Fuego y de los Animales. Están asociados con él los siguientes mámas míticos: $M a$. túna, Sivoláta, Napita, Namsaví, Ili, Suví, Sexá, Kimáku y Sauná; el linaje sacerdotal de los Dingula; los mámas históricos, Labata y Don Labata; Dunginávi, un hijo de la Madre; máma Nakauguí; Nabobá, una hija de la Madre; las Madres míticas, Kaxß̌ikuáma, Simalyingáya y las Hermanas Mayores $\mathrm{Nu}$-uíxa, Nu-Y̌engóna, $\mathrm{Nu}$ híbuldu y Nu-ngauláno; el matrilinaje de las námukalye y además una mujer mítica llamada $A l$ davitsaba, es decir, la madre de Aldauhuíku ${ }^{9}$.

El centro del templo, el punto donde se sienta el máma con ocasión de ciertos ritos, está bajo la protección del quinto hijo de la Madre, el Señor Mulkuéxe. No está marcado por un fogón visible, aunque es el verdadero punto focal del templo y el lugar más sagrado de todo el re- cinto. Mulkuéxe va acompañado por su ayudante Manávi y por Haba Maukui, la Madre del Sapo, animal que siempre está asociado con el concepto del "centro". Además están asociados con este punto las siguientes personificaciones: Hate Teiku, el Padre del Oro; Haba Guxsénse y Hate DZiunk-ka, la Madre y el Padre del Fuego Invisible respectivamente Haba Gerúa, la Madre de la Llovizna, y Haba Eibina, la Madre de Maíz. Por cierto, el carácter mismo de estas asociaciones destaca claramente la importancia de este punto que, según los Kogi, es el centro del universo.

Tanto en los mitos y ritos, como también en las enseñanzas particulares de los mámas se hace referencia a estas asociaciones, sean las de los fogones o sean las del centro. Desde su adolescencia cada hombre debe aprender en más y más detalle los nombres y características de estas personificaciones sobrenaturales o históricas que se relacionan con cada uno de estos cinco puntos y así se crea en los hombres un fuerte sentido de identificación con el pasado. El individuo se siente ser un eslabón responsable en la larga cadena de las generaciones y al sentarse en su banquito, al pie del fogón del templo, se sabe observado, acompañado y apoyado a su vez por una gran asamblea invisible que silenciosamente orienta y evalúa los destinos del individuo y de toda la tribu. Por cierto, de nuevo se observa aquí el fenómeno de la inversión, en tanto que los Kogi conciben la comunidad de los vivientes posible sólo en cuanto exista en oposición equilibrada la comunidad de los muertos.

\section{EL TEMPLO COMO OBSERVATORIO}

Hasta aquí he descrito algunos niveles de interpretación simbólica que los Kogi dan al templo como lugar sagrado donde presiden las divinidades y los ancestros, lugar donde se concentra gran parte de la vida religiosa de la tribu. Debo tratar ahora, además del simbolismo, de otro aspecto fundamental, a saber, el templo como instrumento científico de observación astronómica.

En el ápice de los templos principales, ubicados en los centros ceremoniales, y cuyas puertas opuestas están orientadas este-oeste, se halla un pequeño orificio, un pequeño hueco redondo ${ }^{10} \div$ En aquella parte la paja del techo se ha entretejido y recortado en forma de un anillo de unos pocos centímetros de diámetro, hecho de cierta paja blanca especialmente recogida en los páramos. Por fuera este pequeño hueco está cubierto un framento de cerámica, un pedazo convexo de una olla rota, de manera que queda prácticamente invisible pues desde adentro no se puede reconocer por estar en la parte más alta y obscura del cono del techo. Pero en ciertas ocasiones se abre este orificio; el máma ordena a uno de sus acólitos jóvenes trepar por el interior del techo a la parte 
más alta y retirar la pequeña tapa que cubre el hueco. Ocurre entonces un fenómeno notable; como a las 9 a.m. el sol proyecta un rayo de luz al interior obscuro del templo y un disco luminoso comienza a moverse lentamente por el suelo, para desaparecer aproximadamente a las 3 p.m. cuando la inclinación del techo interrumpe la trayectoria del rayo solar. Si se hace este experimento el día del solsticio de verano ( 21 de junio), el rayo cae sobre el fogón del suroeste a las 9 a.m. de la mañana y la mancha luminosa se mueve luego hacia el este, llegando al fogón del sureste a las 3 de la tarde. En un templo cuyo ápice está a una altura de 6 o 7 metros y que esté provisto de un orificio de 5 centímetros de diámetro, el disco luminoso proyectado en el suelo alcanza un diámetro aproxi mado de 15 centímetros y avanza más o menos $1.40 \mathrm{mts}$. por hora. En los días de equinoccios (21 de marzo y 21 de septiembre) el rayo recorre el diámetro del templo, entre las dos puertas y en el solsticio de invierno de diciembre) el rayo marca la línea entre los fogones del noroeste y noreste. Es un hecho que los templos se construyen en posiciones tales que, en el curso del año, el sol alcanza a marcar en el suelo un rectángulo delimitado por los cuatro fogones. Es pues el mismo sol que define el espacio sagrado.

El templo kogi es un observatorio solar. La observación del rayo que penetra por el ápice permite a los mámas establecer en cualquier día del año la posiciór exacta del sol y de predecir así el comienzo o el fin de las estaciones. El proceso es tan simple como preciso: en cualquier día de sol los mámas pueden comprobar la posición de éste, pueden saber duánto falta aún para los días precisos de los solsticios y equinoccios, y así tienen la posibilidad de coordinar el calendario agrícola con el calendario ritual. Aproximadamente cada 90 días ${ }^{11}$, los Kogi celebran estas fechas solares con reuniones rituales durante las cuales se baila, se canta, se depositan ofrendas y se cumple con otros requisitos de su religión. Sea dicho aquí que en estas mismas fechas solares, los cuatro Señores de las "esquinas del mundo" se trasladan de un fogón al otro, en el sentido del reloj, remplazándose de modo que cada uno llegue a ocupar durante tres meses uno de los cuatro puestos. Esta rotación se designa como matéisi y es, desde luego, de gran importancia para el desarrollo del ciclo ritual anual, desces pueden pasar muchos meses sin que los mámas se dediquen a esta forma de observación astronómica; viendo las salidas o puestas del sol en el horizonte, se contentan con constatar que el astro sigue su marcha normal y que el ciclo de las estaciones se está cumpliendo con su ritmo acostumbrado. Pero a veces el sol no parece moverse de un modo previsible; ocurre que una estación seca se prolongue o que, por lo contrario, las lluvias no cesen y que los cultivos comiencen a sufrir graves daños. Es entonces cuando los mámas proceden a la observación detallada y cuando hacen destapar el orificio del ápice del templo. Siempre-aún en épocas de lluvia-habrá entonces unos ratos de sol y tan pronto como se proyecte un rayo sobre el suelo, el máma puede reconocer inmediata-

11 Diciembre 21 a marzo $21=89$ dias; marzo 21 a junio $21=92.8$ dias; junio 21 a sep. tiembre $21=93.8$ dias; septiembre 21 a diciembre $21=89.9$ dias. mente la posición solar y saber entonces si se trata de alguna irregularidad que, eventualmente requiere su atención e interferencia directa. A veces, cuando se prolonga un verano o cuando las lluvias amenazan las cosechas, los mámas de varios centros ceremoniales se ponen de acuerdo y observan simultáneamente los rayos del sol sobre el piso obscuro del templo, para interpretar su avance y poder predecir el fin de la calamidad. Esta observación puede durar tres o cuatro días pero a veces puede prolongarse por varios meses.

Debo explicar aquí en más detalles estas eventuales 'irregularidades' en los movimientos del sol, ya que ellas constituyen un problema importante para los mámas.

Según los Kogi el sol, como divinidad, es un hijo de la Madre Universal y se identifica con Mulkuexe, el personaje que ocupa el centro del quincunce. En otros contextos el sol se identifica con Sintána, el primer hombre de la creación. Según la tradición el sol nació en Takína, y su padre fue Sehukúkui ${ }^{12}$. La madre lo destinó a subir al cielo para dividir el tiempo en noche y día, y en estaciones, para marcar las faenas agrícolas. Dada la vital importancia que este papel tiene para la tierra y sus habitantes, el carácter y las funciones del sol se convirtieron en tema de gran preocupación.

El sol es esencialmente un hombre, un hombre kogi, y como tal reune en sí todas las virtudes y defectos propios de un kogi. Veamos brevemente cuál es la imagen de este hombre solar.

La primera esposa del sol fue el sapo (maukuí), pero pronto se separaron pues era una mujer vieja y fea, quien además engañaba al sol con otros hombres ${ }^{13}$. El sol se casó luego con su propia hermana, la luna (su) y ella continúa siendo su legítima esposa. Un episodio importante en la vida del sol fue su relación incestuosa con su propia hija, el planeta Venus (enduksáma), y además un tercer nexo incestuoso une al sol con la Madre. El sol tiene varias concubinas (gaya), todas constelaciones celestes, a las cuales visita periódicamente. Estas relaciones familiares del sol, sus embrollos sexuales y sus peleas con ciertas concubinas celosas, se elaboran en muchos mitos y cuentos que frecuentemente subrayan el carácter esencialmente 'humano' del sol.

Como personificación masculina el sol tiene pues un carácter ambivalente y a veces se dice de él que "está jugando", es decir, se conduce de un modo irresponsable e imprevisible. Se dice que, a veces, no se conduce como un adulto y que además está sujeto a súbitos cambios de ánimo.

12 Es decir, el principio de la obscuridad dio origen al principio de luz

13 Según algunos mitos fragmentarios, el Sol se casó primero con la Culebra, pero la abandonó. El mager una mujer vieja designada El matring el sapo como Madre de la Tierra por el máma, experiencia que se elabora luego en la oposicón enke sanónimo de vagina. El matri. y el sapo como monstruo sabterráne. El nombre del sapo (mán. monio con la Luna es el modelo de la institución matrimonial según la cual un hombre kogi se casa primero con una mujer mayor que él, y luego con una más joven, a veces la hermana menor de la primera.
Las dos mujeres simbolizan entonces la Luna Vieja y la Luna Nueva. 
La bóveda celeste es la "casa del sol", es su templo, y el recorrido diario del astro está marcado por sus lentos pasos con que va de una puerta a la otra, del este al oeste. Pero este mismo recorrido diario se interpreta por parte de los Kogi en diferentes formas. En una imagen vemos al sol triunfante, con la cara cubierta por una máscara resplandeciente de oro de la cual salen los rayos brillantes que penetran el espacio. Dos mámas -Uldihúe y Huingelda - lo llevan sobre sus hombros y el astro tiene que cuidarse de mostrar su cara sólo de perfil porque al voltearla del todo hacia la tierra, ésta se quemaría. En otra imagen se describe al sol caminando por el cielo llevando su banquito para sentarse a veces a descansar y a masticar coca ${ }^{14}$. Su hija Venus le trae comida cuando tiene hambre o de vez en cuando una de sus concubinas se acerca para darle a comer. Del gorro ${ }^{15} \mathrm{del}$ sol es de donde salen sus rayos y cuando - al mediodía - se quita este gorro y sigue su camino con la cabeza descubierta, entonces cesa el calor y el aire se hace más fresco. En otra imagen se muestra al sol como un anciano que camina muy lentamente apoyado en un bastón largo ${ }^{16}$. El rayo de luz que penetra al templo es su bastón y en su vacilante progreso se puede medir la marcha del anciano astro por el cielo. Al medio día el sol llega a un gran abismo, tan profundo que alcanza hasta nuestro mundo; poniendo su bastón como puente de una orilla a la otra, el sol atraviesa la grieta y sigue su camino; descansa de vez en cuando en un banquito que le trae una de sus concubinas. Pero en otra imagen el rayo del sol se interpreta como la varita (sugi) con la cual se saca la cal del calabacito cuando se mastican las hojas tostadas de la coca. El templo es el poporo del sol, es su calabacito de cal donde introduce su varita para buscar con ella cal en las cenizas de los fogones. Y otra imagen aún: al penetrar con sus rayos al templo, el sol come dos veces al día, como lo hacen todos los hombres. Tiene su desayuno en un fogón y su comida en otro, hasta que, después de seis meses, llega a la línea equinoccial. De allí en adelante desayuna y come en los otros dos fogones. En todos los cuatro fogones son las mujeres de los cuatro Señores de las esquinas del universo, las que le preparan la comida y las que atienden al sol durante su visita. Y finalmente otra imagen: al interpretarse el templo como útero cósmico, el sol aparece como un principio procreador masculino. Su rayo fálico penetra por el ápice del techo e impregna el útero de la Madre con nueva vida. En los días de los equinoccios, al medio día, el rayo del sol meridional cae sobre el centro del espacio sagrado y fertiliza allí el centro del universo ${ }^{17}$.

Todas estas imágenes que los Kogi manipulan en sus interpretaciones simbólicas del templo son proyecciones,a escala gigantesca. No obstan-

\footnotetext{
14 El banco de oro del Sol se llama se-kaldauxe.

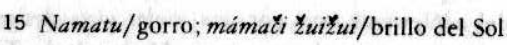

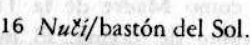

17 El territorio kogi está aproximadamente a $11^{\circ} \mathrm{N}$, de manera que el sol no pasa por el cenit, pero tengo entendido que los mámas saben adaptar el orificio del techo de tal modo que en los equinoc. cios el sol marca el centro del templo.

te sus características humanas, el sol es un gigante que domina todas la dimensiones, desde la bóveda celeste hasta el templo más pequeño. Es te inmenso poder concentrado en manos de un ser sujeto a emociones tan humanas, representa desde luego cierto peligro. ¿Qué ocurríía si el so se cansase y se durmiese? ¿Qué ocurriría si se demorase demasiado en un mismo lugar? ¿Cuáles serían las consecuencias de un nuevo incesto entre el sol y su hija Venus? En el este, en las profundidades del espacio existe una mujer en forma de astro que a veces seduce al sol con sus encantos y lo hace perderse. Ella es káldabauku (eclipse) y se describe como muy bella y "toda negra y azul". Cuando el sol desaparece con ella, los mámas ordenan extinguir todos los fogones en las casas y proceden a producir el fuego nuevamente con un berbiquí ritual (gemá) y con yesca preparada de ciertos hongos secos $(\text { kalyis-kuka })^{18}$. Este acto ri tual induce al sol a volver en sí y a reasumir su curso acostumbrado. $\mathrm{Pe}$ ro el hecho de un eclipse causa consternación.

Las variaciones climáticas y los cambios cíclicos que se pueden constatar en el curso de décadas, también parecen indicar al máma que e sol no sigue una ruta fija, sino que su influencia sobre la tierra está ex puesta a variaciones que pueden tener graves consecuencias para los cultivos y para otros aspectos esenciales para el bienestar de la humanidad.

Podemos resumir entonces la situación así: vista por los Kogi, la función principal del sol consiste en marcar las estaciones, en propiciar e crecimiento de las plantas, y en mantener un equilibrio adecuado entre días de lluvia y días con cielo despejado. Sin embargo, el sol no es de todo fiable; a veces se esconde por largos ratos y otras veces trata de quemar la tierra. También hay eclipses y en otras ocasiones se acerca peligrosamente a ciertos planetas. Así, el sol no se cree que tenga un iti nerario perfectamente fijo e inmutable y es necesario entonces controla su curso. Los mámas deben llamar la atención del sol sobre sus eventuales fallas y deben apaciguarlo cuando está enojado y pone en peligro la vida de la gente. El sol debe ser controlado no sólo en su propio curso, sino también en cuanto a sus múltiples relaciones con lo otros astros. Los templos no se usan como observatorios permanentes, sino son puestos de control del sol que permiten verificar -en cualquier momento - sus movimientos; se trata de marcar su progreso y, en caso necesario, de corregirlo con invocaciones.

\section{EL TEMPLO COMO TELAR DEL SOL}

A continuación pasaré a referirme a otra imagen de la cosmovisión kogi, en la cual se amplían los conceptos hasta ahora descritos. Para comprender este nuevo aspecto, debo comenzar con una breve incursión al terreno de la tecnología textil. (Figura 4).

18 KáliY-kuka/ árbol-de oreja; son pequeños hongos semicirculares que crecen sobre troncos podri dos y que, en el vernacular español, se llaman 'orejita de palo' 
Los Kogi como algunas otras tribus indígenas del norte de Colombia, cultivan el algodón y utilizan los hilos de sus fibras para tejer sus vestidos. Hombres, mujeres y niños se visten con estas telas manufacturadas en sencillos telares verticales y, a diferencia de sus vecinos los Ika y los Sanhá, los Kogi rechazan los tejidos comerciales modernos e insisten en usar sólo el producto tradicional de su propia tecnología. Aunque las mujeres hilan a veces el algodón, a ellas no les está permitido tejer sus vestidos y las telas siempre están hechas por sus padres o maridos. Son los hombres los tejedores y dicha actividad está imbuida de un complejo simbolismo que se relaciona estrechamente con el tema de los templos.

El telar (žakuan-kalda) es muy sencillo y consiste de un marco rectangular formado por cuatro maderos fuertes, reforzados por dos varas diagonales puestas en cruz. Estas seis partes están amarradas con cuerdas en sus uniones y forman un cuadrángulo que mide aproximadamente $1.40 \mathrm{mts}$. por cada lado. Para la manufactura de las telas se necesitan luego varios objetos más, todos hechos de madera, a saber: 1) una bobina (Zakuanči asigí) el "macho de la tela", formada por una vara delgada de unos 40 cms. de largo y sobre la cual se enrolla el hilo con el cual se va a tejer; 2) una paleta o 'espada' pesada (saxkálda) que sirve para apretar el hilo horizontalmente; 3) una vara (sesakalda) de sección circular en la cual se amarran los elementos de una parte de la urdimbre y que sirve para cambiar de plan; 4) otra vara delgada (eldunxualda) que une los dos extremos de la tela; y 5) una varita corta (guisguína) a manera de grueso alfiler, que sirve para separar - con un rápido movimiento en sentido horizontal- los hilos verticales de la urdimbre.

El primer paso en la manufactura de una tela consiste en poner la urdimbre en el telar. Se comienza por la esquina derecha inferior y, al envolver el hilo verticalmente sobre las dos gruesas varas horizontales, se le pasa por la varita delgada central (eldunxualda) de tal manera que, al terminar el tejido, ésta se saca horizontalmente, abriéndose así la tela en una sola pieza rectangular. Una vez puesta la urdimbre, se coloca la vara separadora de los dos planos y en seguida se introduce la espada volteándola longitudinalmente hasta que su ancho esté horizontal, de modo que abre un espacio de sección triangular que permite la introducción de la bobina. Esta se pasa rápidamente hacia la izquierda (o la derecha), el hilo se templa y en seguida se pone el filo de la espada en posición vertical y se aprieta con él el hilo de la trama. Ahora se saca la espada, se tira del separador para cambiar de plano, se introduce la espada y nuevamente se coloca un hilo de la trama al pasar la bobina en la dirección opuesta.

Tanto la vestimenta en sí, como los detalles de su manufactura son de gran sencillez y no ofrecen mayores variaciones, ni tecnológicas ni de decoración. Pero estas apariencias engañan; tras este artefacto de uso diario se manifiestan ideas y asociaciones que forman un mundo simbólico insospechado.

En una de las principales imágenes de la cosmovisión kogi, nues- tra tierra se concibe de forma plana y rectangular, tal como un telar. Por encima de esta superficie terrestre se escalonan otras tierras más, todas en forma de telares y sujetas a diversas divinidades, cada nivel hacia abajo o hacia arriba siendo algo más reducido en extensión que el anterior, pues la forma del cosmos es entonces la de dos pirámides unidas por sus bases. Al combinar entonces los dos elementos simbólicos fundamentales, los Kogi tienen como modelo del cosmos un telar atravesado por un huso perpendicular.

Este modelo expresa las observaciones astronómicas de los Kogi. Las dos varas horizontales representan las líneas solsticiales, cada una delimitada por el cruce de las esquinas que indica la salida o la puesta del sol en los días de 21 de junio y 21 de diciembre. La línea equinoccial (21 de marzo y 21 de septiembre) está representada por la varita central del telar (eldunxualda) que, al sacarla del tejido terminado, permite desplegarlo hacia arriba y abajo. Esta misma imagen se aplica luego al templo. El piso de éste se considera como un gran telar; los cuatro fogones marcan las cuatro cruces formadas por las varas verticales y horizontales del marco de madera del telar. Las dos varas oblicuas que dan estabilidad a este marco, forman entonces la cruz que señala el centro del templo.

Pues bien: la mancha luminosa del rayo solar va de un fogón al otro en los solsticios, pero cada día avanza muy levemente en dirección norte o sur, según la declinación del sol. Este movimiento ha do origen a un concepto de gran importancia en el pensamiento kogi, a saber, la idea de que el sol es un gran tejedor. Al imaginarse nuestra tierra como un inmesnso telar alrededor del cual el sol se mueve en un movimiento espiral de vaivén, los Kogi dicen que "el sol está tejiendo" /máma nyuí źakuan gau. Mientras que en la primera metáfora vimos que la Madre estaba hilando, en esta nueva metáfora vemos al sol entretejiendo el hilo en un inmenso lienzo. Visto a esta escala cósmica se dice oue el teje "la tela de la vida" (alúna žakua); lo mismo ocurre entonces cuando el rayo del sol -o la "mano del sol"- teje en el telar delimitado por los cuatro fogones del templo. Según el decir de los Kogi, es la misma pone la urdimbre en el marco del telar, mientras que es el sol que entreteje la trama. Al iniciar su tejido el día del Año Nuevo kogi (21 de junio), el sol comienza a tejer en el cruce opuesto del telar, es decir en la esquina inferior izquierda, y coloca el hilo cotidiano de su trama de la izquierda a la derecha. Pero tan pronto como el sol desaparece bajo el horizonte, sus rayos penetran la estructura inversa del templo, es decir, entran por el ápice del templo invisible que complementa el modelo de la doble pirámide (o doble cono) bajo tierra. Es el llamado "sol negro" (máma nyui abaxse) que teje de noche y que coloca entonces el hilo de la trama de la derecha a la izquierda. Según dicen los Kogi, cada tejido tiene entonces dos lados: el lado externo que es el lado del día, el lado iluminado, mientras que el lado interior, el que -en un vestido- está en contacto con el cuerpo, es el lado de la noche, el lado obscuro. (Figura 5).

El simbolismo del hilar y tejer penetra todas las dimensiones del 
pensamiento indígena. Según los Kogi "vivir es pensar" y el acto de hilar se compara con el proceso del pensamiento humano (alúna hanguté), con la meditación que debe ir "por un hilo". Hilar es una actividad solitaria; los Kogi dicen: "Cuando uno está hilando, uno piensa. Así sentado, torciendo el hilo sobre el muslo, uno piensa mucho: en el trabajo, en la familia, en la gente - todo". Luego, al sentarse la persona frente al telar, estos pensamientos se entretejen en una tela y esta tela es la vida; el vestido que lleva el Kogi es su vida. "Solamente uno mismo teje la tela de su vida" (éisua alúna-žakua iskuími gau-itéi) reza una de las solemnes recitaciones cuando los hombres están reunidos en el templo, cuando los mámas hablan del destino humano y de la gran soledad en que el hombre debe buscar la superación moral. Tejer es un acto público, es una actitud social, es participar en la vida del grupo. Pero el resultado final es el 'tejido de la vida' y la calidad de un tejido siempre depende de dos factores: de la calidad del hilo y de la habilidad del tejedor. Dicho en otra forma: la calidad de la vida individual es determinada, según los Kogi, por la manera como la persona se interrelaciona con su grupo.

En cada templo kogi hay un telar; a veces está puesto contra la pared exterior, bajo el alero del techo, pero con frecuencia está dentro del templo, al lado de una puerta. Y no está allí para un fin utilitario eso sería una profanación - sino siempre representa un elemento de enseñanza. Para los Kogi, tejer es una disciplina y a veces los mámas ordenan a hombres culpables de algún mal comportamiento, tejer, como parte de una enseñanza moral. En repetidas ocasiones he visto disciplinar así hombres, desnudos acurrucados delante del telar del templo que tejían frenéticamente, mientras que a su lado estaba el máma, de pie, enojado, golpeando al culpable en la cabeza con el palito de la cal y exclamando: “Te haré aún respetar la tela!”.

Pero la imagen pastoril y serena del hombre que medita delante de su telar es sólo una de tantas en que los Kogi escrutinan los problemas de la existencia humana. Como siempre su pensamiento opera sobre diversos niveles y lo que en un contexto parece ser sublimación o viva fantasía, en otro contexto aparece como escueta realidad. Así, hilar y tejer también pueden interpretarse como actividades sexuales y entonces el simbolismo de los diversos objetos materiales se transfiere al cuerpo humano y a sus funciones físiológicas. Para los Kogi las motas de algodón representan una materia seminal y el acto de torcer hilos de este material tiene una marcada connotación sexual. Asimismo, el acto de tejer simboliza el coito. Visto sobre este nivel de interpretación, el marco del telar es un cuerpo humano, es una mujer. La barra horizontal superior la designan como la 'cabeza' (sánkalda); los dos postes laterales son las 'caderas' (axaldukua); las varas cruzadas son los 'brazos' (gula), y la barra horizontal de abajo es "la parte donde se trabaja' (aximúnakalda agekué), expresión que alude a la región genital. El telar cubierto con la urdimbre se considera directamente como un cuerpo femenino y la bobina que se introduce entre los hilos de la urdimbre y que lleva la trama, es Zakuan $\nvdash_{i}$ asigí/el "macho de la tela'. Del mismo modo, el modelo cos- mico de un inmenso telar atravesado por un huso, representa simbólicamente la unión sexual.

En lo que se refiere a esta interpretación del acto de tejer, las tradiciones míticas son muy claras. Citaré aquí un fragmento, para dar un ejemplo del nivel metafórico en cuestión.

En el comienzo de los tiempos la Madre era la única que poseía el conocimiento del arte textil. Comenzó a tejer telas pero no permitía a nadie que la mirara en el acto. Cuando los primeros hombres vieron es tas telas y preguntaban cómo las había hecho, ella contestaba con palabras evasivas. Pero una noche su hijo Seiźnakua fingió estar enfermo y dormido para observar a la Madre a través de una rendija. Vio entonces como ponía la urdimbre en el telar y como tejía. Seižánkua trató de imitar lo que había visto e hizo una tela. Cuando la Madre la vio exclamó: “¿Quién ha estado observándome?". Pero ya entonces todos los hombres estaban aprendiendo a tejer. Al darse cuenta de que su secreto ha bía sido divulgado regaló dos grandes pelotas de hilo a Seižánkua. Ahora él y su mujer se ponían a tejer pero, a su vez, prohibían a su hijo a observarlas. Pero éste ya se había dado cuenta porque entonces en todas partes los hombres ya estaban tejiendo.

\section{ASTRONOMIA Y CALENDARIO KOGI}

Debo recapitular y explicar en más detalle algunos aspectos fundamentales de la astronomía kogi.

Hay varias categorías de lugares de observación astronómica. La más sencilla consiste de un pedrejón de uno o dos metros de alto, cuya parte superior forma un filo recto natural a lo largo del cual se puede visar hacia un punto en el horizonte. Tales rocas se encuentran con fre cuencia cerca de los centros ceremoniales o de las viviendas de los má mas y, a veces, están marcadas de un pequeño petroglifo ${ }^{19}$. Otra categoría consiste de algún lugar plano en campo abierto, donde se ha marcado un punto fijo desde el cual el observador puede seguir con la vista una alineación que muestra en cierta dirección; el punto fijo es, generalmente, una 'silla' de piedra, es decir una pequeña laja horizontal que sirve de asiento bajo, y detrás de la cual se ha colocado verticalmente una laja, delgada pero ancha, que sirve de espaldar. A partir de este punto se ex tiende luego una o varias alineaciones que consisten de cortas estela verticalmente enterradas que marcan una visual que se continúa luego pasando - por ejemplo - por una roca de grandes proporciones o por la cima de una colina no muy distante, para terminar en el horizonte donde habrá un pico o una incisión en un filo montañoso. Este punto e el horizonte marca entonces algún fenómeno celeste. Otra categoría de

19 Muchos petroglifos en Colombia, no sólo en la Sierra Nevada de Santa Marta, parecen relacionarse con los conceptos astronómicos de los indigenas 
observación se basa en un gnomon, una estela o especie de columna de piedra, cuya sombra marca la posición del $\mathrm{sol}^{20}$. Finalmente, la categoría más elaborada está representada por el templo dentro del cual se hace la observación al examinar el rayo de luz que un astro hace caer a su interior obscuro. (Figura 7).

Un templo debe estar incorporado dentro de un sistema de direcciones cósmicas (śikuáxalda) y el hecho de que - como observatorio- deba ocupar una posición fija y prácticamente inalterable, presupone una planificación minuciosa. Valles orientados en dirección este-oeste, como, por ejemplo- el valle de Hukuméiži, el de Cerúa o varios valles de las cabeceras de los ríos Ranchería y Cesar, se prestan naturalmente para la observación de los puntos solsticiales y de las salidas de los astros. Pero en las poblaciones de la vertiente occidental de la Sierra Nevada estas observaciones son imposibles y así los mámas de aquella región se dedican a registrar las puestas de los astros. Por cierto, la gran importancia de la línea suroeste-noroeste se observa hasta en las pautas de poblamiento. En centros ceremoniales como Takina, Makotáma o Čerúa, se trata en buena parte de observaciones cenitales y lunares. Las exigencias de visibilidad en cierta dirección explican entonces por qué algunos templos importantes se fundaron en regiones donde las demás condiciones de vida son algo precarias.

Los resultados de las observaciones astronómicas varían, desde luego, según el método empleado. Algunos modos de observación permiten fijar los puntos de los solsticios y equinoccios, o de las salidas o puestas de ciertos astros. Un gnomon permite determinar por la longitud y la dirección de la sombra proyectada, el acimut y la altura del sol, y un templo permite fijar un espacio delimitado por los solsticios y equinoccios y así dividir el año en cuatro períodos, fijando además la posición meridional del sol. Por cierto, la función del templo o de otras técnicas de observación, no es la de medir comparativamente sino de fijar el resultado de la medición ${ }^{21}$.

20 Según informaciones fragmentarias, algunos mámas poseen instrumentos de madera para observar el sol. Este dato tiene especial interés en vista de un reciente trabajo de Digby (véase Bibliografia) sobre un instrumento astronómico mesoamericano que aparentemente combinaba un gnomon con un astrola. bio. Sea dicho que algunos mámas kogi poseen un gorro de cuatro aristas que imita este instrumento.

21 Es muy posible que algunos sitios arqueológicos colombianos se relacionen con observaciones astronómicas. Me parece que son de especial interés ciertos valles o planos que, por su orientación esteoeste, ofrecen buena visibilidad para observar las salidas y puestas de muchos astros. Me refiero por ejemplo aquí al altiplano de Tunja, al valle de Villa de Leyva, a la región de Sogamoso y a ciertos sectores de la Sabana de Bogotá, para mencionar sólo algunos lugares. Los llamados 'cojines del Diablo', dos discos talla. dos en la roca, en un alto situado en el perímetro urbano de Tunja (Boyacá), quizás son un puesto de observación de solsticios y equinoccios. En el sitio de El Infiernito, entre Villa de Leyva y Santa Sofia, existe una alineación de más de 20 grandes bloques de piedra, que muestra en dirección este-oeste (coincidiendo su dirección oriental con la posición de la Laguna de Iguaque). Cerca de este lugar yacen gran. des piedras en forma de menhires toscamente labrados, con una escotadura anular tallada en un extremo, des piedras en for de mentremo, que parecen taber fer iguaque y Guatavita, tan importantes en la cosmogonia y mitologia de los Muiska, ocupan probablemente posiciones astronómicas relevantes para el calendario indigena. Los Templos del Sol y de la Luna que se men. cionan en las crónicas españolas, para Sogamoso y Chía respectivamente, pueden haber sido observatorios
astronómicos como los aquí descritos para los Kogi.
Al hablar de los templos como réplica de la estructura cósmica, como ambientes uterinos o como observatorios astronómicos, me he referido siempre a cierta forma de construcciones, a saber aquellas que se de signan como templos 'femeninos' y dentro de los cuales se observan los aparentes movimientos del sol. Es verdad que, en un cierto sentido geneaparentes movimientos del sol. Es verdad que, en un cierto sentido gen templos de aldea son 'masculinos' y las casas de vivienda que los rodean son 'femeninas' y se designan como "sus mujeres" ( $\mathrm{nu}$. huíxi múnd $\nvdash_{i}$ ); pero en un sentido más preciso y específico hay dos categorías de templos, de acuerdo con el sexo que se les atribuye. Los dos se distinguen exteriormente por la forma de sus ápices y esta diferencia es indicativa de sus distintas funciones. Los templos de los cuales he tratado hasta aquí son 'femeninos' $y$, aparte de su función cronométrica, se interpretan como el "cuerpo de la Madre". Un máma me dijo "Entrar a una casa, a un templo o a una montaña, es lo mismo como entrar al cuerpo de la Madre por la vagina". Como he dicho ya, los ápices de estos templos consisten de una especie de embudo o cono invertido hecho de varas (aldunkana, alduxalda) de macana, unidas por dos más círculos de bejucos. Ocasionalmente, sobre todo cuando se deterioran y se sueltan estos bejucos, las varas se van bajando por su propio peso y quedan horizontales, formándose una rueda plana, en lugar de un cono invertido. Otras veces, este efecto de rueda o disco horizontal se obtien ya durante la construcción y se produce intencionalmente. En el centro del embudo o rueda se colocan una o dos varas verticales (hu-súkalda) de unos $50 \mathrm{cms}$. de altura, por lo general envueltas en paja, y sobre ésta se colocan a veces varias ollas de cocina, en ocasiones la una puesta sobre la otra, ya que han sido perforadas para este fin. Ocasionalmente el máma ordena poner una pequeña vara horizontal entre las dos verticales y suspender de ella varios 'murciélagos' (nyuízii), entretejidos en forma de cruz. Por lo demás, en el fondo del embudo el máma coloca -o hace colocar - una cantidad más o menos grande de fragmentos de cerámica (uldu-kuldu) que se ponen con la parte convexa hacia arriba y, en su interpretación más simplista, se dice que impermeabilizan el techo contra la lluvia. Todo el embudo está sostenido por una base anular de varillas cubiertas de paja, que forman una especie de cojín entre el techo y el ápice. Estos ápices en forma de cono invertido se llaman comúnmente munsa o munsei, palabra que significa 'amanecer' $y$, en un sentido transferido, 'vagina' o 'nacimiento'.

Aquí se plantea nuevamente el problema de la interpretación sobre diversos niveles, tan común entre los Kogi. Al ver en el templo un modelo del cosmos, el ápice es el nadir, el punto más alto del último mundo (xatsal-nulang) donde presiden Máma MusuSi y Haba Nyexan. Al mismo tiempo el nadir es el extremo del eje cósmico que es el huso de la Madre Universal. Al interpretarse el templo como útero, el ápice es considerado como el órgano sexual; los 'murciélagos' tejidos también son órganos fe-
meninos o, en otra imagen, se refieren a la menstruación; las ollas perforadas por las varas verticales simbolizan el acto sexual, y los fragmentos cerámicos en el fondo del embudo representan un elemento seminal fertilizador. El rayo del sol se designa entonces como falo (nyuíti alu. na kalgua) o como la "flecha del sol" (nyuí̌i sesa), un sinónimo común. 
Al interpretarse el templo como montaña sagrada, el ápice viene a representar al sol que asciende por la montaña por su vertiente oriental; luego pasa sobre su cima, y baja por su vertiente occidental. Aun lo 'murciélagos' se convierten entonces en pequeñas réplicas del sol. Al in terpretarse al templo como el recipiente de cal (sugi) y al rayo solar como la varita (sukalda) para extraerla, el ápice es considerado como aquella parte del calabacito que está cubierta por una delgada capa de cal ( $k a$ lamútsa), depositada allí con el tiempo por la varita humedecida de saliva. La metáfora de la saliva corresponde entonces al simbolismo de los fragmentos cerámicos que dicen representar la cal y, en otro sentido al semen masculino. Cuando el templo se interpreta como la "cocina de sol" (hiY̌iba-lula), el ápice se convierte en un simple escape para el humo de los fogones. Pero la interpretación más frecuente es aquella en que el templo se designa como el útero de la Madre, como una "casa de carne". "El ápice munsa es el corazón de la Madre; es su vagina -es lo mismo", constató un máma. Pero este mismo 'cuerpo de la Madre' es la "casa del Sol", su construcción y orientación corresponden a los solsticios y sus dos puertas están orientadas para marcar la línea equinoccial. Es pues una construcción en función del Sol y de todo lo que este astro significa para los Kogi.

La segunda categoría está constituida por los templos que se designan como 'masculinos' y que se hallan sólo en algunos de los centros ceremoniales de mayor importancia. Estos templos se distinguen exteriormente por la forma de su ápice que, en lugar de ser circular, es alargado y se parece a una larga barra horizontal. El ápice consiste de tres partes: un armazón alargado de unos 3 metros de largo, puesto transversalmente sobre la cumbre del techo, y cubierto de paja como éste. Sigue luego un cuerpo plano de paja entretejida, también horizontal alargado y con los mismos contornos, y de éste salen casi horizontalmente una serie de varas de macana entrelazadas por tres o cuatro vueltas de bejucos. También el interior de este armazón contiene múltiples fragmentos cerámicos pero carece de las varas verticales, de las ollas esfondadas y de los 'murciélagos' suspendidos.

Estos templos están destinados exclusivamente a ciertos ritos a cargo de un grupo reducido de participantes. En su interior se hallan cuatro fogones pero en lugar de contener además algunos objetos tales como telares, bancas largas, hamacas o cerámicas, hay sólo un asiento al lado de cada fogón. Los ápices de estos templos se designan como sauli/pene, y sus extremos laterales se dice que son 'ojos' $(u b a)$. Además, estos ápices están puestos en ángulo recto a la línea que une las dos puertas las cuales, no siempre, están alineadas en dirección este-oeste. Estas diferencias formales sugieren pues que dichos templos se utilizan para fines rituales y astronómicos distintos a los arriba descritos.

Tomemos el caso de Takina, que según los Kogi, es el centro de mayor importancia y donde se levantan los templos más sagrados. Una de las tres construcciones es un templo coronado por un gran ápice en forma de embudo, pero por lo demás difiere de otros templos similares en varios aspectos. En primer lugar, este templo sirve como lugar de re- unión ritual a las mujeres de los mámas. Tiene una sola puerta que mira hacia el este. En el interior hay cuatro fogones asociados con cuatro divinidades, cuatro Madres: en el NE Haba Uxáne-yang, en el SE Haba divinidadátsáma, en el SO Haba Sivaldé-yubang, en el NO Haba Kunté yumang, y en el centro Haba Sei-ni-yumang. Estas Madres corresponden en su orden a los Señores Sehukúkui, Aldauhuíku, Kun`avitaueya, Seiそánkua y Mulkuexe respectivamente, en su posición en uká (21 de junio) y efectúan la misma rotación en el sentido del reloj, cada 90 días aproximadamente. En segundo lugar, no obstante el ápice en forma de embudo, en este templo no se hacen observaciones astronómicas.

Los otros dos templos tienen ápices alargados transversales. El principal templo tiene dos puertas colocadas sobre un eje orientado noroes te-suroeste, mientras que el ápice está orientado perpendicularmente, es decir, va en dirección noreste-suroeste. En otras palabras, los dos ejes forman una cruz que tiene la misma orientación, tal como las dos varas cruzadas del telar que se simbolizan en el piso del templo. En el interior hay cuatro fogones pero el resto del mobiliario es escaso y consiste de cuatro pequeños bancos, uno al pie de cada fogón. Este templo está destinado exclusivamente al ritual que se relaciona con la conjunción mensual de Sol y Luna, celebrado por un grupo pequeño de mámas. En el ápice está un orificio que consiste de un tubo (seulú) de cerámica, de unos $15 \mathrm{cms}$. de diámetro, por unos $30 \mathrm{cms}$. de largo, colocado verticalmente en el centro del techo. A través de este tubo cae el rayo de la luna en determinadas noches, así como el rayo del sol en ciertos días. El tercer templo también tiene un ápice alargado pero este se encuentra orientado de Norte a Sur, mientras que las dos puertas opuestas están alineadas en dirección este-oeste. En el interior hay cuatro fogones, bancas largas y asientos individuales, hamacas, ganchos para colgar objetos, y ollas para tostar las hojas de coca. En este templo se reunen los mámas de menos status, así como los hombres y los jóvenes iniciados.

Es importante observar aquí que ya desde las primeras horas de la mañana las varas que salen horizontalmente de los ápices transversale (90 en el templo mayor y 44 en el menor) proyectan sobre el techo sus sombras delgadas, las cuales al mediodía - y a veces a medianoche-se ven
como líneas negras casi verticales, que van desde la parte más alta hasta abajo. La parte superior del techo cónico de estos templos, directamente debajo del ápice, está pintada de negro con una solución espesa de agua y carbón vegetal. El aprendiz (noákubi) del máma principal, después de haberse preparado ritualmente con ayunos, trepa de noche al techo y pinta esta parte con ukúlyi, un tinte negruzco obtenido al disolver en agua una cantidad de tallos finos carbonizados, de cierta paja llamada mukui $n i$, recogida en los páramos cercanos. Las sombras de las varas que sale de los ápices son observadas en detalle por los mámas, quienes reconocen por medio de ellas ciertas posiciones meridionales de los Astros. El templo principal, con su eje en cruz de quincunce, se relaciona con estas observaciones, y el templo menor - cuyas puertas marcan la línea equinoccial-, también parece relacionarse con estos movimientos astrales. Dejo abierta la pregunta de si los Kogi saben calcular eclipses. Dentro del con226 
texto de su religión, este fenómeno es el foco de grandes preocupaciones y sería de suponer que la predicción de tales eventos haya sido objeto de sus especulaciones ${ }^{22}$.

Las observaciones astronómicas de los Kogi tienen como uno de sus fines principales la comprobación de un orden cósmico, que es fundamento y modelo del orden social. Este orden cósmico se observa en la dimensión espacial y en la cronológica y conduce, ante todo, al establecimiento de un sistema uniforme de fechas, es decir, un calendario. El primer paso consiste en observar y fijar las grandes divisiones del tiempo, a saber, los cuatro períodos delimitados por los solsticios y equinoccios. El hecho de que estos coinciden con las estaciones - dos lluviosas y dos secas - da a esta división cuatripartita el carácter de un esquema mormativo para las faenas agrícolas. El segundo paso consiste en subdividir estos períodos de aproximadamente 90 días cada uno, en unidades más pequeñas, siendo entonces la luna el modelo de aspectos individualizados. Superpuestos a estas dos secuencias desiguales se encuentran luego otros fenómenos cíclicos, a saber, el desarrollo de la vida humana individual y el desarrollo de animales y plantas. La interacción entre todos estos fenómenos cíclicos forma entonces la base para la economía y la sociedad y para todos los mecanismos de adaptación. La concordancia de estos modelos celestes y biológicos está bajo el continuo escrutinio de los mámas.

El calendario kogi o, mejor dicho, los calendarios y su coordinación, están aún muy deficientemente conocidos por mí. El año solar se inicia, según el decir de muchos indios, con el solsticio del 21 de junio cuando aparecen al amanecer las Pléyades (uká). A partir de esta fecha el tiempo se divide por meses lunares $(s u)$ que se calculan como el tiempo transcurrido entre una Luna nueva y la otra. Cada mes se identifica con cierto animal, el cual está representado por una constelación visible al amanecer. Estos animales son las concubinas (gaya) del Sol que éste visita en el curso del año. Hasta aquí los datos coinciden; pero al tratar del número y de la secuencia exacta de estos meses lunares, aparecen dudas y contradicciones. Ello se debe, por una parte, al hecho de que sólo pocas personas conocen los detalles del calendario que, en sus aspectos rituales, pertenece a un campo del cual no se habla públicamente; por otra parte, las correlaciones entre el año solar y los meses lunares son tan elásticas y aun arbitrarias que sería difícil buscar en ellas una pauta perfectamente fija. Se trata esencialmente de trece meses lunares, de aproximadamente 29 días cada uno, pero a veces los Kogi mencionan 9 meses o dos series de 9 meses cada una, y otras veces se mencionan 18 meses de 20 días. La secuencia es aproximadamente la siguiente: el primer mes es uká (Pléyades) que, para los Kogi es el coatí (Nasua rufa). Uká es la concubina preferida del Sol porque el coatí es - según los indios - un animal amable y limpio, que le gusta comer cosas dulces y que

es "buena cocinera". De ahí el Sol pasa a tami, nombre del pequeño re cipiente vegetal en el cual los hombres guardan el zumo de tabaco concentrado y que está representado por las Híadas. La tercera luna es sei $k u$, el alacrán, cerca de Aldebarán (ubikve?), en la constelación de Tauro. Viene luego huso, el cangrejo, aún en la misma constelación y, como quinta luna, neb-siža (puma), representado por el Cinturón de Orión. E próximo mes es neb-tasi (jaguar azul) ${ }^{23}$, representado por la Espada de Orión. Sigue nebbi (el jaguar), en la constelación del Can Mayor, luego nebbi-yéldyi (nutria), y, finalmente, tarbi, la culebra (Bothrops atrox). donde el Sol llega hacia el solsticio del 21 de diciembre. Esta secuencia de nueve meses lunares parece estar bastante bien comprobada, pero luego se mencionan los nombres de neb-క̌ki乏̌ abaxse (Felis jaguarundi), uása (Conepatus), híbixa (Mustela), sinsi (Mus) y otros cuya posición dentro del calendario no es segura. Sea dicho que los Kogi dividen el día en unidades de 3 horas cada una: 6 a.m., 9 a.m., 12 a.m., 3 p.m. y 6 p.m.; según algunos, el día comienza a las 12 a.m.

En la concordancia de estos meses lunares con el año solar, se considera que el Sol no pasa siempre el mismo número de días en la casa de cada concubina. Por ejemplo, en "casa de ukâ" el Sol se demora hasta 20 días para aprovechar de la buena comida, pero en la "casa de tárbi" 20 días para aprovechar de la buena comida, pero en la casa de tárbi mal humor; cuando el Sol le alcanza la mochila llena de frutos que le ha traído, ella la bota a sus pies y lo insulta, negándose a darle de comer. La culebra y el coatí son enemigas y nunca pueden estar visibles en el firmamento al mismo tiempo. Con tami el Sol se demora unos tres días; con huso unos cinco a siete, con neb-siźa entre cuatro y siete días. De esta manera hay gran amplitud para ajustar las discrepancias entre las secuencias. Por cierto, la imprecisión en estas correlaciones no indica que lo mismo ocurra en otros cálculos. Parece que muchos mámas llevan cuentas muy detalladas sirviéndose de instrumentos mnemotécnicos tales como varas con muescas.

Los Kogi reconocen seis fases principales de la Luna. La Luna Creciente (saka visa) se desgina como $t a S i /$ verde, y lentamente se pone $a b u$. $\chi_{i} /$ blanca, al volverse Luna Llena (saka su-mankukui). En el Cuarto Menguante se designa como saka tšuiža y de color atseక̌i/rojo, volviéndose luego más negra/su-abaxse, hasta que, como abaxse/negra, desaparece por tres noches, sólo para reaparecer luego como Luna Nueva (saka seivákse). Estas divisiones, por cierto, son muy amplias; lo que cuenta en realidad es la relación entre todas las 28 fases lunares con las posiciones solares y con las constelaciones. Los Kogi creen que el desarrollo biológico de algunos animales que son dañinos para los cultivos, coinciden con las fases lunares y que ciertos gusanos, insectos, roedores o aves se comerán las semillas o retoños de un cultivo recién establecido, sólo en ciertos días y no en otros. La mayoría de las plantas culti-

23 La palabra tasi significa tanto el color verde como el azul. En ciertos contextos significa cre. cimiento o falta de madurez. 
vadas debe sembrarse cuando hay "luna blanca", pero aún entonces se corren ciertos peligros. Es necesario pues reconciliar el calendario agrícola - por lo menos en algunos meses - con las fases lunares, lo que se expresa entonces en hablar, por ejemplo, de uká abuči, uká abaxse, o hu. so taši, según sea el caso. (Figura 8).

He mencionado que en el interior de los templos femeninos, casi en su parte más alta, está suspendido un objeto llamado pispiska, del cual se sirven los hombres para separar los hilos cuando quieren torcer una cuerda gruesa. Aparentemente se trata de un artefacto muy rudimentario pero en éste se combinan un gran número de aspectos astronómicos y simbólicos de gran complejidad. El objeto consiste de dos anillos hechos de una liana, unidos por dos varitas puestas en cruz (Figura 8). El diámetro de cada anillo puede ser de unos $20 \mathrm{cms}$. y las varitas miden aproximadamente 40 centímetros de largo. El objeto está suspendido en una cuerda que se amarra en el punto donde se cruzan las varitas, de manera que los dos anillos quedan perfectamente balanceados. La cuerda pasa luego por un pequeño anillo hecho con una rama doblada en círculo y que está amarrado en el techo, y la cuerda baja luego hacia una de las puertas del templo, donde su otro extremo se amarra en uno de los maderos gruesos oblicuos que sostienen el techo. Al soltar este extremo de la cuerda, la pispiska se puede hacer descender por su propio peso.

La interpretación que los Kogi dan a la forma de este artefacto es, en un principio, muy sencilla; los dos anillos representan los dos solsticios, es decir el recorrido circular del sol en los días 21 de junio y 21 de diciembre; las varas cruzadas muestran entonces las líneas formadas por las posiciones diarias del sol. La pispiska es pues un modelo tridimensional de los solsticios, modelo que - por cierto- nuevamente muestra cinco cruces dispuestos en un quincunce. Su nombre significa 'cosa que revuelve', 'cosa que da vueltas alrededor de sí misma', derivado de la expresión pis-pis-pis con la cual los Kogi describen la acción de rodar o de revolver algún objeto. Pero la pispiska tiene además un uso eminentemente práctico en tanto que sirve como ayuda mneomotécnica para aprender el calendario. Cada parte de los anillos y de las varitas tiene un significado fijo; la persona toma el objeto en la mano izquierda y muestra con el índice derecho las posiciones de las diversas 'casas' por las cuales pasa éste u otro fenómeno. Se comienza con $u k a ́$, en el punto donde el extremo de una varita está amarrado a un anillo. A continuación se recitan las fases lunares (ataši, abuči, atseši, abaxse), junto con una larga enumeración de las plantas que deben sembrarse o las frutas que deben cosecharse, y de las diversas clases de lluvias que caerán para hacer germinar y crecer las semillas. Se cree que todas las constelaciones y estrellas individuales pasan por fases sucesivas similares a las de la Luna, de manera que en la recitación se tienen en cuenta estos cambios. A ello se añaden en cada caso algunas palabras dirigidas a los animales nocivos así como referencias a diversos aspectos rituales que se relacionan con cada fecha. Siempre marcando con el dedo los puntos de los meses lunares, se da la vuelta al anillo y se avanza luego por las varas en dirección sur, para pa230 sar al anillo opuesto y al punto terminal de la 'casa de la culebra', en e solsticio de diciembre. El aprendizaje del calendario, manejando la pis piska, es una tarea larga que, teóricamente, todos los hombres deberían cumplir ${ }^{24}$

El calendario ritual superpuesto a la correlación de los calendario solares y lunares, se divide en varios aspectos. Por un lado se fijan en é sole celebran en valas fechas para las grandes ceremonias colectivas que se celsticios y equinoccios. rias poblaciones grandes, generalmente en los solsticios y equila y se En estas ceremonias se prepara chicha, guarapos con el máma canta y en las últimas noches los hombres se confiesan con equeñas ofren das simbólicas que luego depositará en un lugar sagrado. Por otro lado, e dienen un cacácter más exclusivo y más personal. En los centros ceremoniales se celebran ritos que, a veces, están atendidos por sólo muy pocos individuos y otros ritos se efectúan en lugares solitarios en los páramos, en duos y otros ritos pencia de unas pocas persocuevas o en las orillas de las lagunas, en presencia de agregan las fechas nas - a veces solo de un ciclo vital. Con excepción de los ritos funerarios, estos no se celebran individualmente sino en ciertas fechas solares y para varias personas.

El siguiente es un somero resumen del calendario ritual. En Hukuméiłi y Séižua se celebran ceremonias colectivas en los dos equinoccios, men el equinoccio de septiembre y en el solsticio de juen San Francisco en el equinoccio de septiembre y en el solsticio de junio; en Séižua y Hukuméiži se baila además en neb-skiž $i$, en Santa Rosá en nebbi, y en uká hay bailes en San Francisco, San Jose y Cendukua. Después del solsticio de diciembre, se baila en Séižua en honor de Teiku. En los equinoccios de marzo y septiembre se baila en varios pueblos en un ritual relacionado con la fruta diciembre se celebra se atribuyen efectos narcoticos, y en el solsticio palma de las tierras baen Takina el rito de huká, relacionado con una palma de las tierras bajas. También en esta fecha se apaga el fuego en todas partes y se enciende luego ritualmente en los templos. Los ritos de 'bautizo' (gaull) y de 'matrimonio' (huaséi $\mho_{i}$ ), es decir, la entrega del calabacito de cal, se efectúan alrededor del equinoccio de septiembre y el ritual para las 'almas' de los difuntos se hace en el solsticio de diciembre, por parte de los mámas especializados en estos ritos. El calendario ritual también determina mas especializados en estos ritos. El calendario los cultivos, o en que se

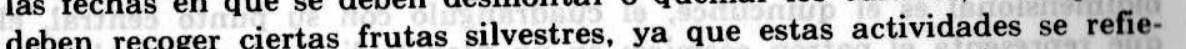
ren muy directamente a los dueños sobrenaturales de la vegetación.

Pero eso son, en el fondo, problemas de menor importancia si se tienen en cuenta las relaciones fundamentales - "biológicas', para decir

24 Las Madres míticas de la pispiska son Haba Se-nunaling y Haba Se-nyimang. Otras interpreta ciones de la pispiska son las siguientes, según un informante: "La pispiska es una comunicación con Kuisbángui y Mulkuéxe. Uno sacude la cuerda y dice: 'Señor ;Debes hacer justicia! Tal y tal cosa está
pasando!' Otro informante dijo: "La pispiska guarda el mundo más alto; ella da poder al mundo". "Wu pal 
así- que según los Kogi se desarrollan entre los astros, ante todo entre el Sol y su mujer, la Luna. Cuando, cada mes, la Luna desaparece por tres noches "para cambiar de vestido", ella se junta con su "esposo negro", con el "Sol negro"/máma nyuí abaxse, en su casa en el mundo de las tinieblas, para aparecer luego nuevamente en el cielo, rejuvenecida y bella. La Luna Creciente es entonces la representación del embarazo que, según los Kogi, culmina en la Luna Llena, cuando "todo tiene semilla" y cuando "la Luna es buena" (assiang-'̌a narldó). Este cambio de Luna Vieja a Luna Nueva, es un modelo importante, pues forma la base para la costumbre kogi de casarse primero con una mujer vieja y luego, después de algunos años, con una joven. La observación de la conjunción entre Sol y Luna en el inframundo, es decir, el cálculo exacto del momento cuando se efectúa este contacto fertilizador, es una de las preocupaciones principales de los mámas. Pero los detalles de estos cálculos así como las predicciones que se hacen con referencia a la revitalización periódica del cosmos, se consideran por parte de los Kogi como muy secretas. En efecto, es posible que la importancia de la Luna, en lo que se refiere al sig nificado que los Kogi asignan a la gran complejidad de sus movimientos, sea ocasionalmente más grande que la que tiene el Sol. El Sol y la Luna, como pareja celeste son el modelo de la fertilidad y continuidad.

Al resumir a grandes rasgos la función del templo kogi, sobresalen algunos puntos que parecen de interés destacado, ante todo la representación del templo como modelo cósmico. El templo expresa un principio de orden, de disciplina. Por un lado, cada hombre tiene allí su puesto fijo desde el cual adquiere una perspectiva de los demás, de sus orígenes y de sus relaciones mutuas. Por el otro lado, al incorporarse a este cosmos, el individuo queda convencido de las regularidades que rigen el universo. Aquí no se trata necesariamente de un principio religioso sino de un gran mecanismo de integración cultural. La visión cuatripartita del mundo, con sus cuatro regentes, y las innumerables asociaciones de la estructura cósmica y de la mecánica celeste, se identifican con los detalles más mínimos de la existencia humana. Y aunque este grandioso orden parezca rígido e inmutable, el mismo Sol, con su vaivén, con su eterno curso espiral y con sus eclipses, introduce un factor de lo imprevisible, lo insólito que, en último instante, debe enfrentarse sobre un nivel individual.

Este concepto de integración se expresa en formas geométricas muy sencillas que recurren continuamente en la cultura indígena. En un plan bidimensional es el quincunce, el cuadrángulo con su punto central, el que representa el patrón cósmico; en un plan tridimensional es el cono. El primer esquema se deriva de la observación de los solsticios y equinoccios; el segundo, de la observación de un rayo de luz que penetra por un pequeño orificio y que se expande luego en un espacio obscuro. El cono, por cierto, no es otra cosa que un espiral en tres dimensiones y así estos modelos se vuelven intercambiables o se pueden combinar en cadenas, en estratos sucesivos y aún, en etapas temporales.

El viejo máma que, a la vista de su templo exclamó: "Esto es el mundoi Aquí hay de todo!", no pudo haber dicho ni más ni menos.

\section{APENDICE}

El artículo precedente plantea, como es obvio, el problema de los origenes mesoamericanos de muchos conceptos kogi. Para iniciar la discusión de este tema, quiero presentar un breve relato que trata de esta aspecto etnohistórico.

Dicen los Kogi que ellos no son originarios de la Sierra Nevada sino que llegaron en épocas remotas de un país que está situado "en el otro lado del mar". Aquel país se llamaba mulkuaba o mulkama. En esa tierra el sol no pasaba tan alto por el cielo, sino se acercaba más al horizonte. Ocurrió que mulkuaba se incendió y muchos habitantes tuvieron que huir. La tierra estaba en llamas y los que trataban de escapar, tuvieron que cruzar ríos de fuego. Los antepasados de los Kogi huyeron hacia la orilla del mar y allí se embarcaron en nueve canoas. Después de un largo viaje llegaron a la desembocadura del río Palomino, entre la actual Santa Marta y Riohacha. El jefe que dirigía esta migración era llamado Kukulyéxa; él era el 'Señor Jaguar' y era hijo de Kax̧̌́ta, el actual Señor de los Terremotos. Primero fundaron la población de Kukulméiži (el actual Hukuméiži) y poblaron el valle del río Palomino, pero luego se extendieron hacia el valle actual del río San Miguel y fundaron Takina. Según estas tradiciones trajeron de su país de origen algunos objetos de oro, la coca y el conocimiento del arte textil. El jefe Kukulyéxa sabía escribir.

A este relato, los informantes agregaron los siguientes comentarios. Según ellos, $k u k u$ o $k u k u l$ significa "piedra antigua" y alude a los antepasados de la tribu que se habían convertido en piedras o estatuas de piedra (hárldeka) para volverse así inmortales. La migración, dicen que se efectuó hace 52 generaciones.

De mi parte sólo quiero anotar que creo posible que en aquella época -hace unos 900 años - un grupo centroamericano de habla chibcha y de cultura fuertemente influenciada por los Maya, haya emprendido una migración, al ver su tierra amenazada por una erupción volcánica. Sea dicho aquí que la gran importancia que para los Kogi tiene Kaxצ́áta, el Señor de los Terremotos, no guarda proporción con la poca frecuencia de temblores en la Sierra Nevada de Santa Marta. Por otro lado, está de sobra mencionar que Kukulkán fue el nombre maya de Quetzalcoátl. 


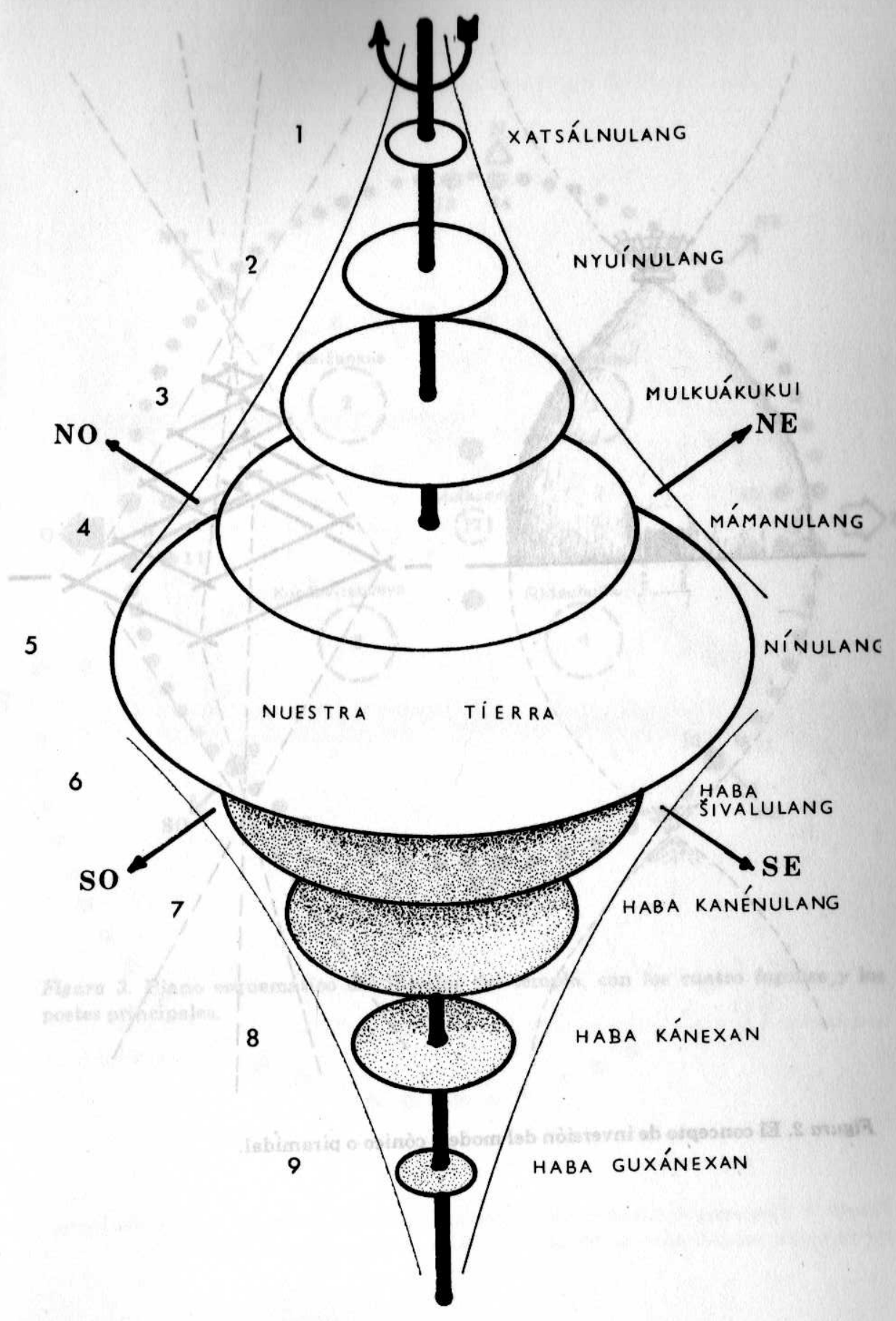

Crossed trapezes: a pre-Columbian astronomical instrument. In: Mesoamerican Archaeology: New Approaches (Norman Hammond, editor), pp. 271-283.

\section{HAMMOND, Norman (editor)}

1974 Mesoamerican Archaeology: New Approaches. University

KERN, Hermann

1976 of Texas Press, Austin.

(1) Fruhe Astronomische Grossgerate aus In dien, Mexico und Peru. Die Neue Sammlung, Staatliches Museum für angewandt Kunst, Munich.

\section{PREUSS, Konrad Theodor}

1926-27 Forschungsreise zu den Kágaba: Beobachtungen, Textaufnah men und sprachliche Studien bei einem Indianerstamme in Kolumbien, Südamerika. Anthropos Verlag, St. GabrielMödling, Austria.

\section{REICHEL-DOLMATOFF, G}

$1950 \quad$ Los Kogi: Una tribu indígena de la Sierra Nevada de Santa Marta, Colombia. Vol. I, Revista del Instituto Etnológico Nacional, Vol. IV, Nos. 1-2, Bogotá

1951

Los Kogi: Una tribu indígena de la Sierra Nevada de Santo Marta, Colombia. Vol. II, Editorial Iqueima, Bogotá

1953

1967

s. a.
Contactos y cambios culturales en la Sierra Nevada de Santa Marta Revista Cólombiana de Antropología, Vol I, pp. 15-118, Bogotá.

Notas sobre el simbolismo religioso de los indios de la Sierra Nevada de Santa Marta. Razón y Fábula, No. 1, pp. 55-72, Universidad de los Andes, Bogotá.

Training for the Priesthood Among the Kogi of Colombia. University of California, Latin American Center, Los Angeles (en prensa). 


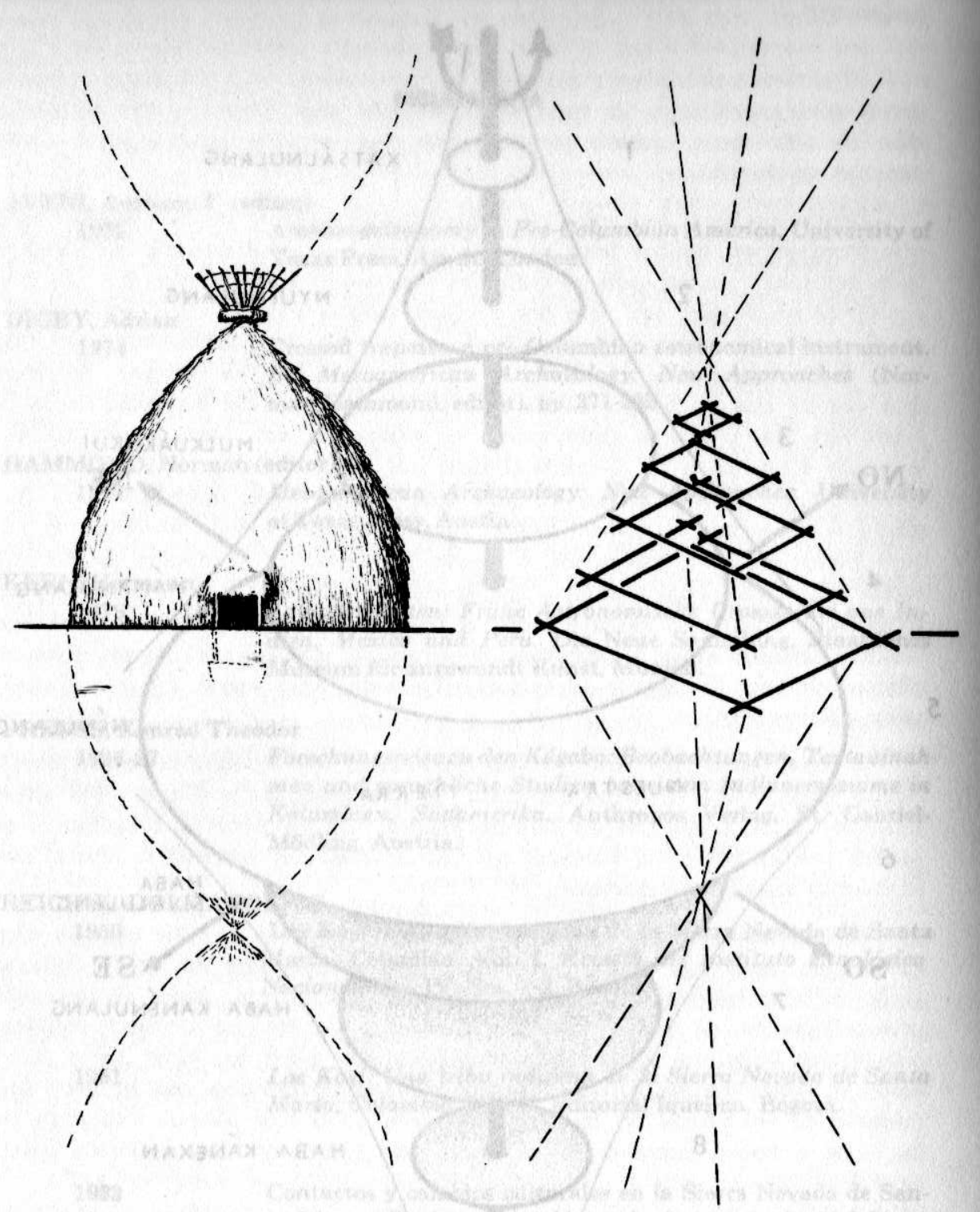

Figura 2. El concepto de inversión del modelo cónico o piramidal.

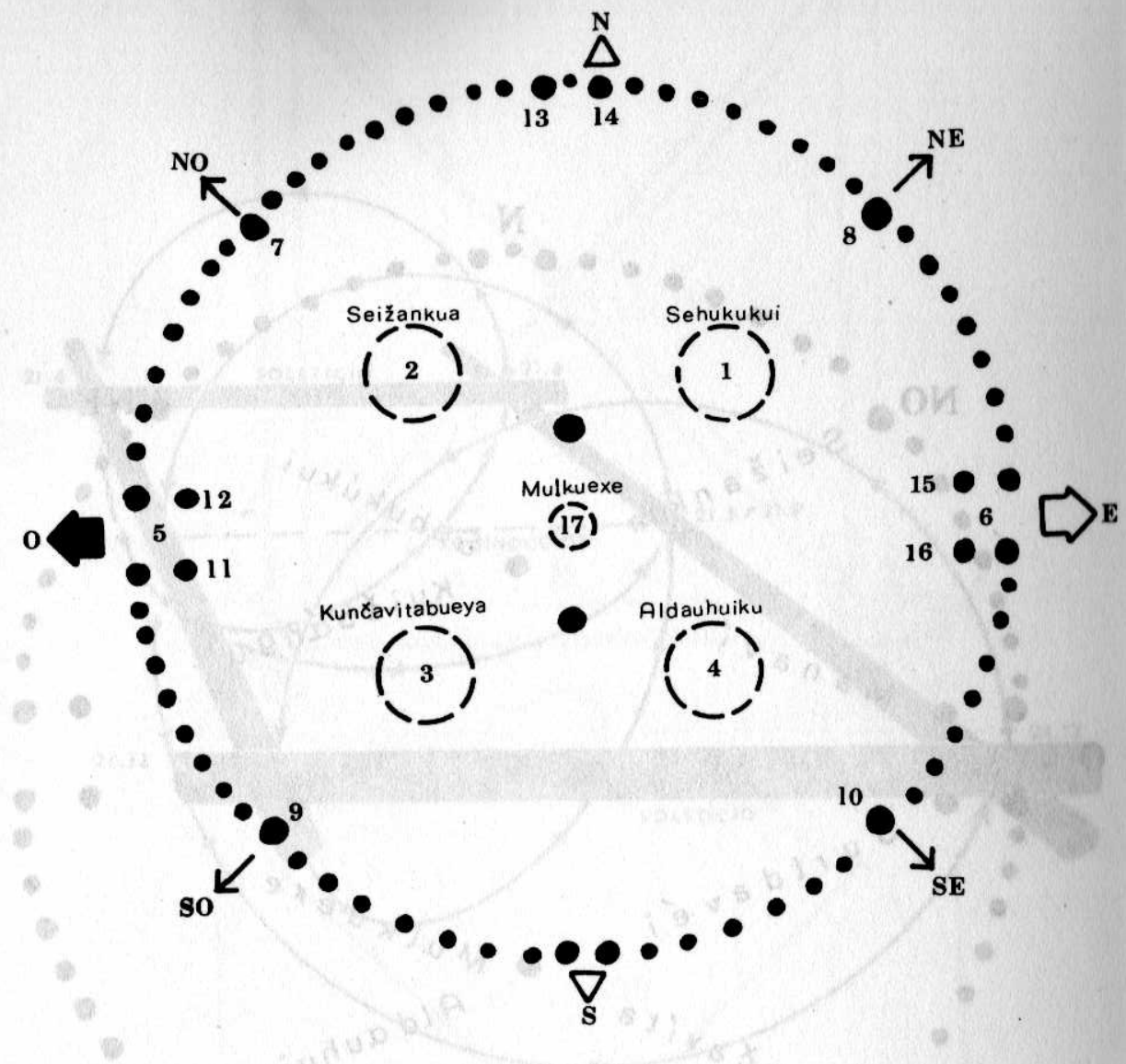

Figura 3. Plano esquemático del interior del templo, con los cuatro fogones.y los postes principales. 


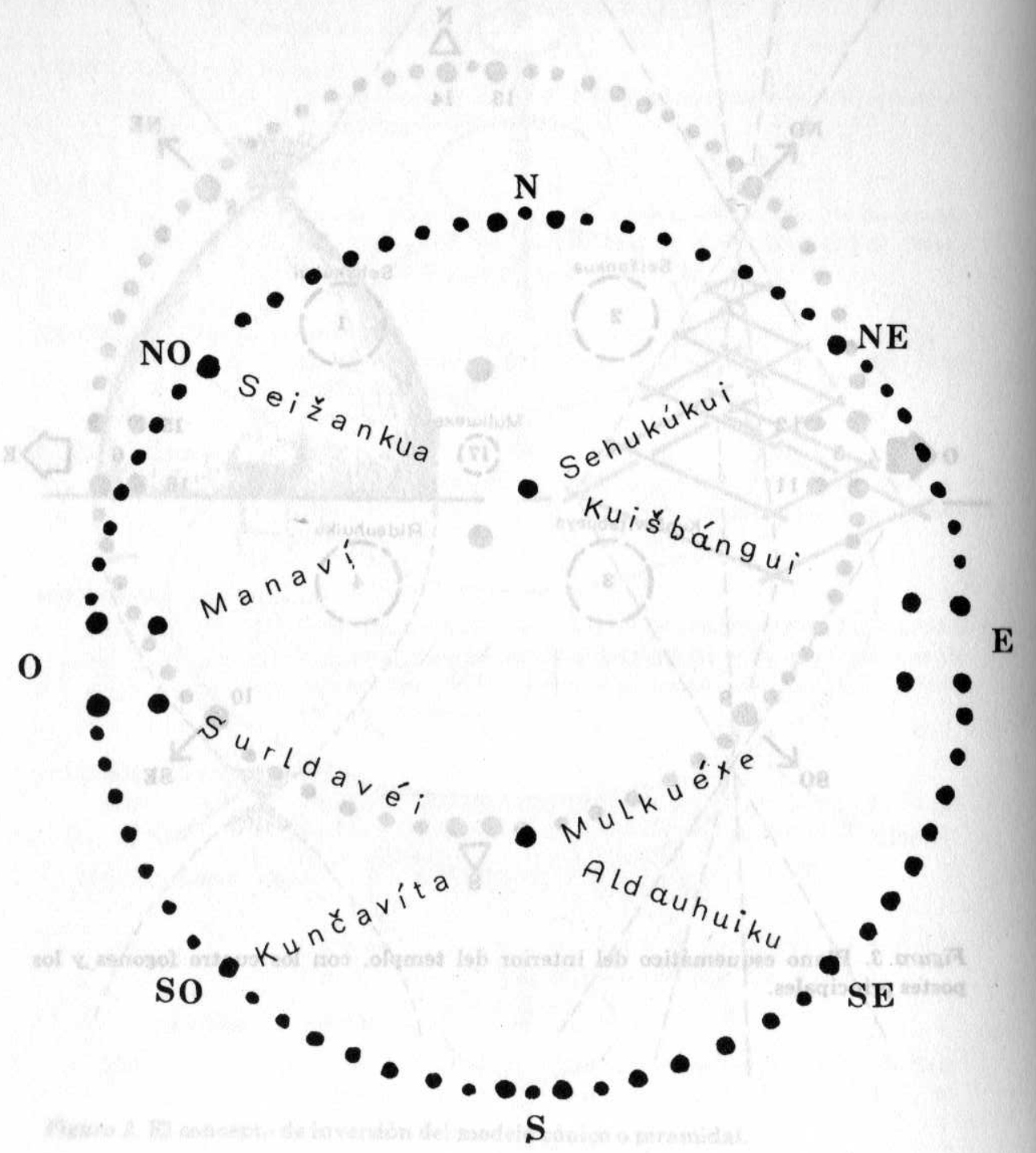

Figura 4. Esquema del interior del templo, indicando las posiciones de las hamacas de los personajes míticos. Manavi y Surldavéi son ayudantes de Mulkuéxe.

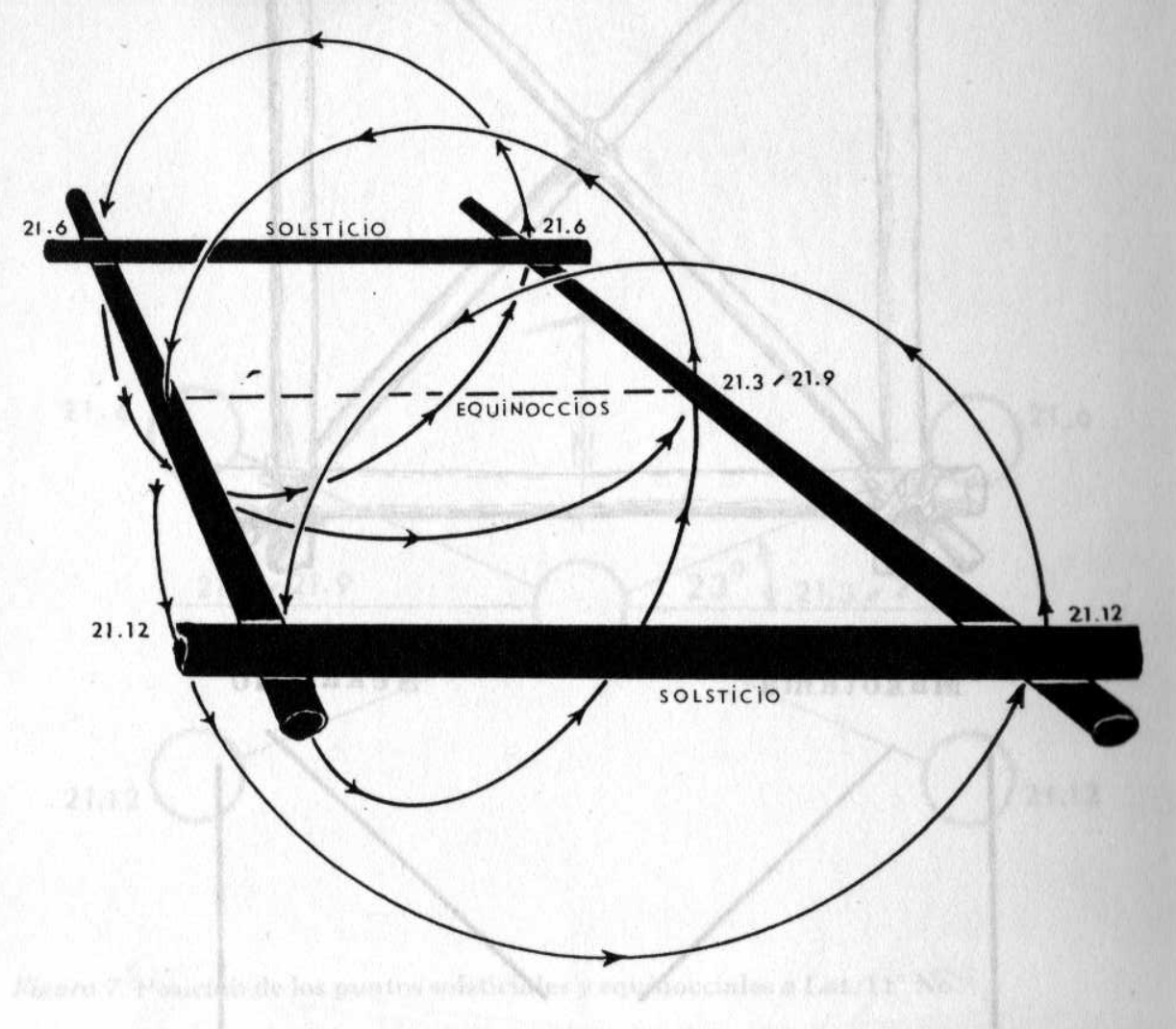

Figura 5. Los movimientos del sol alrededor del telar cósmico, según el concepto geocéntrico kogi. 

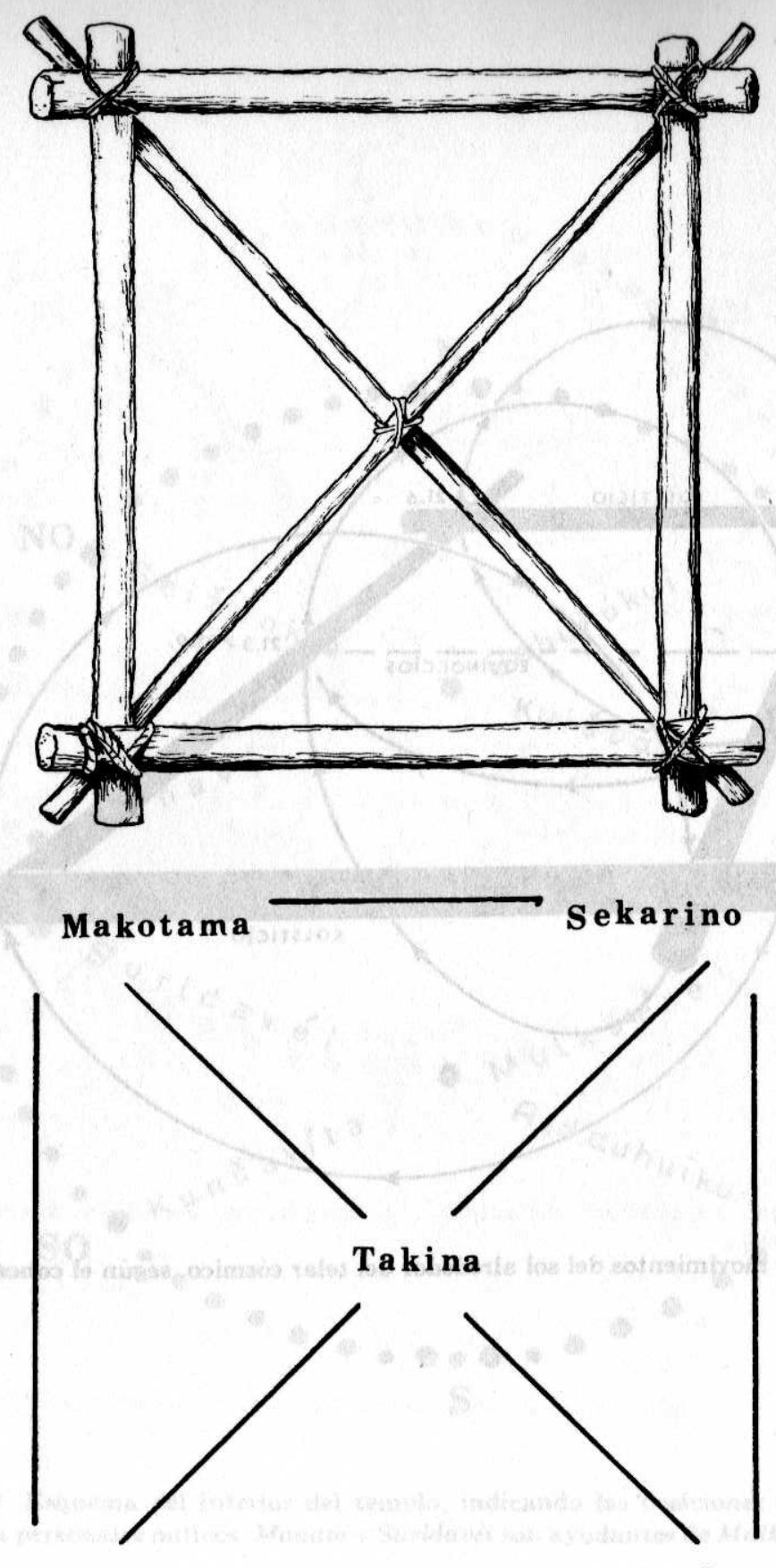

Sankona

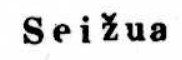

Figura 6. Arriba: El marco del telar con sus cinco cruces; Abajo: El telar como esquema topográfico de los centros ceremoniales.

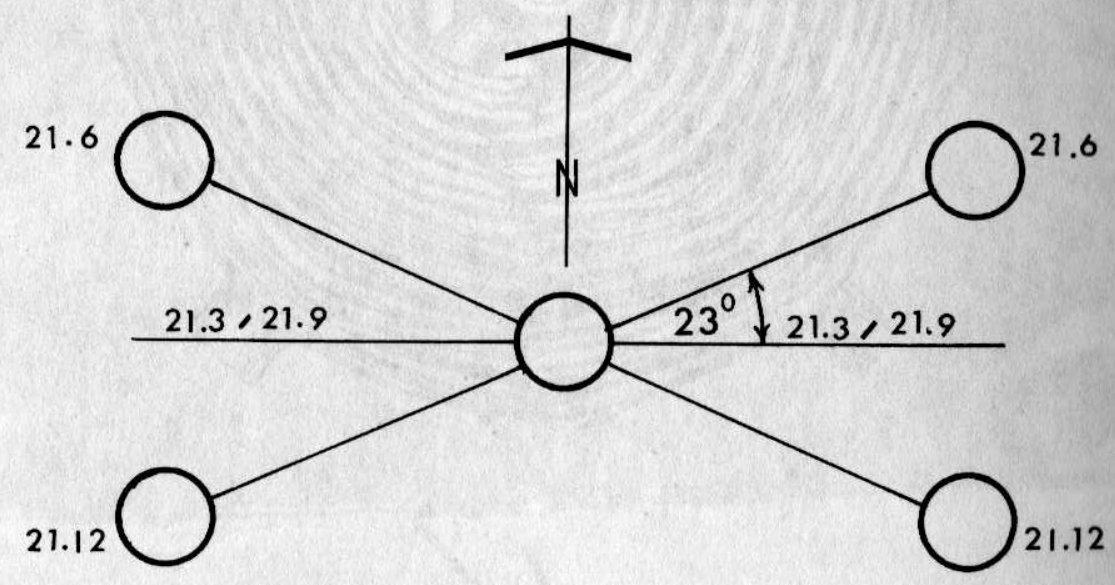

Figura 7. Posición de los puntos solsticiales y equinocciales a Lat. $11^{\circ}$ No.
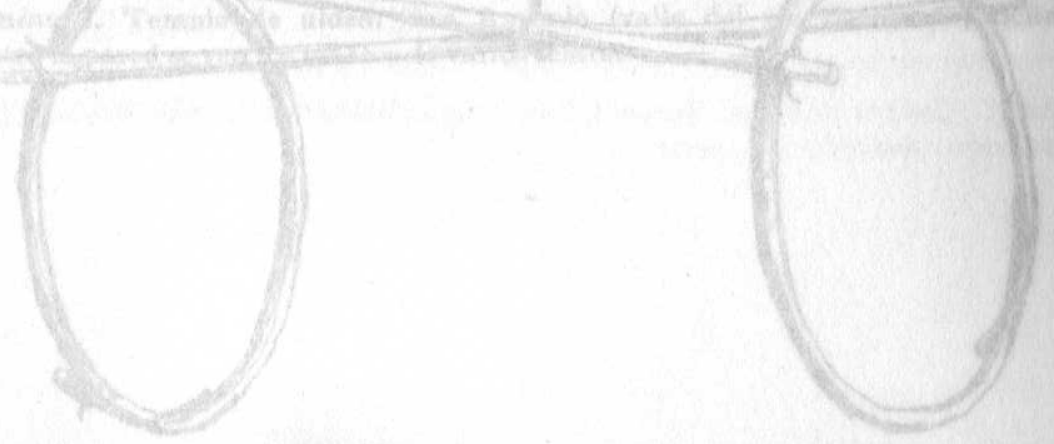

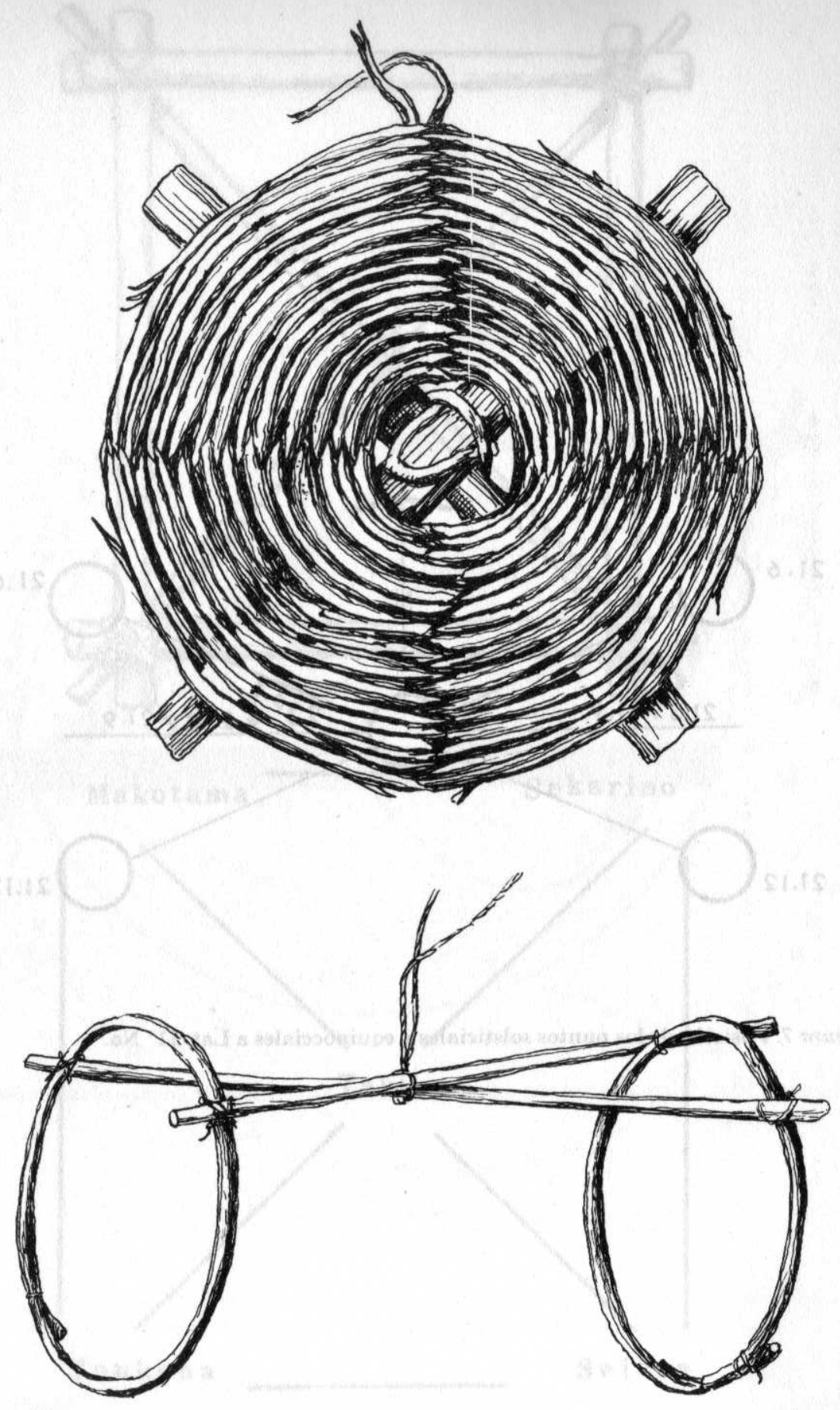

Figura 8. Arriba: 'murciélago' (nyuiži) tejido de espartos; Abajo: modelo del calendario (pispiska)

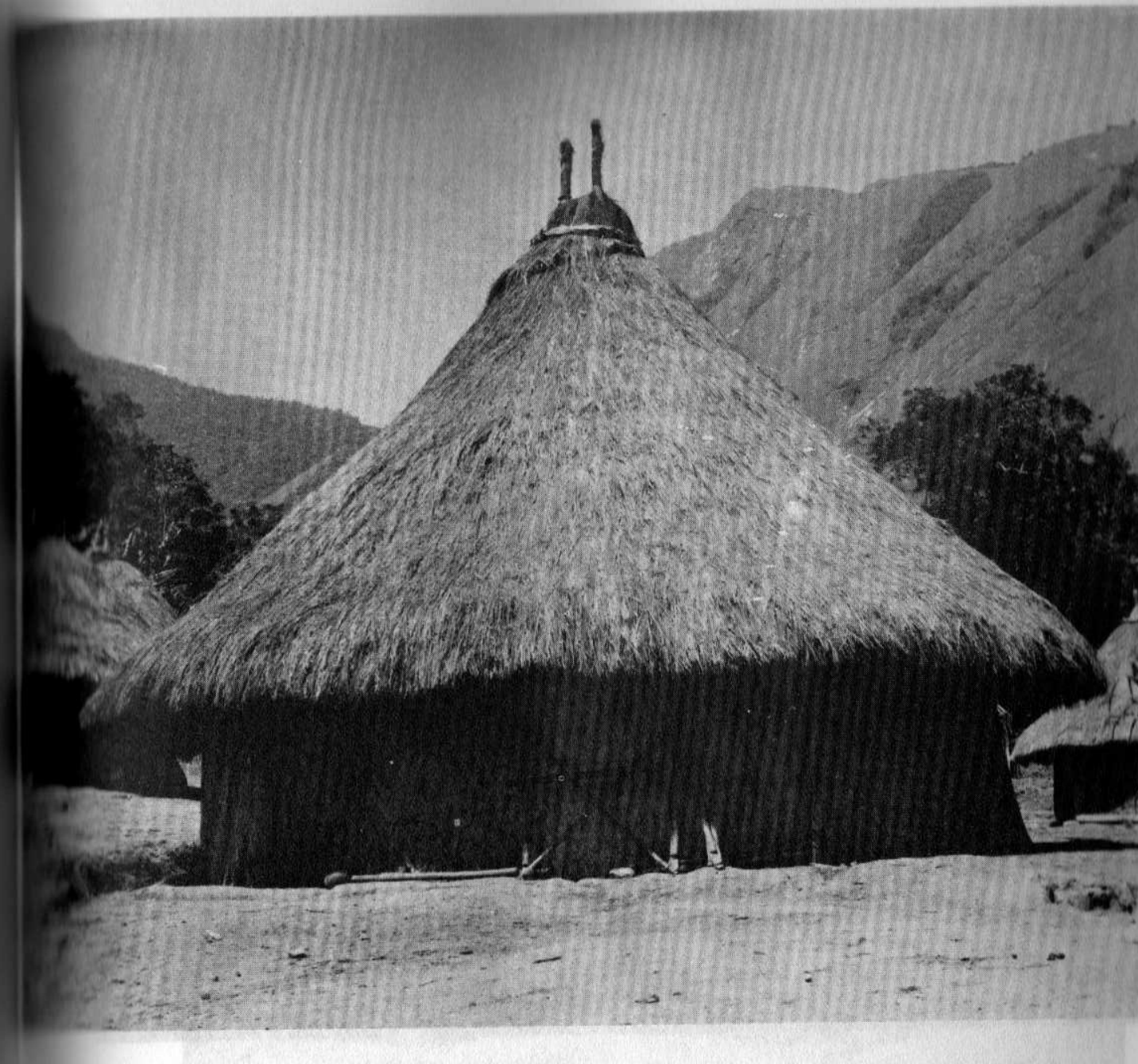

Lámina I. Templo de aldea; San Antonio (valle del río Garabito). Inclinados contra la pared se ven los marcos de varios telares. 


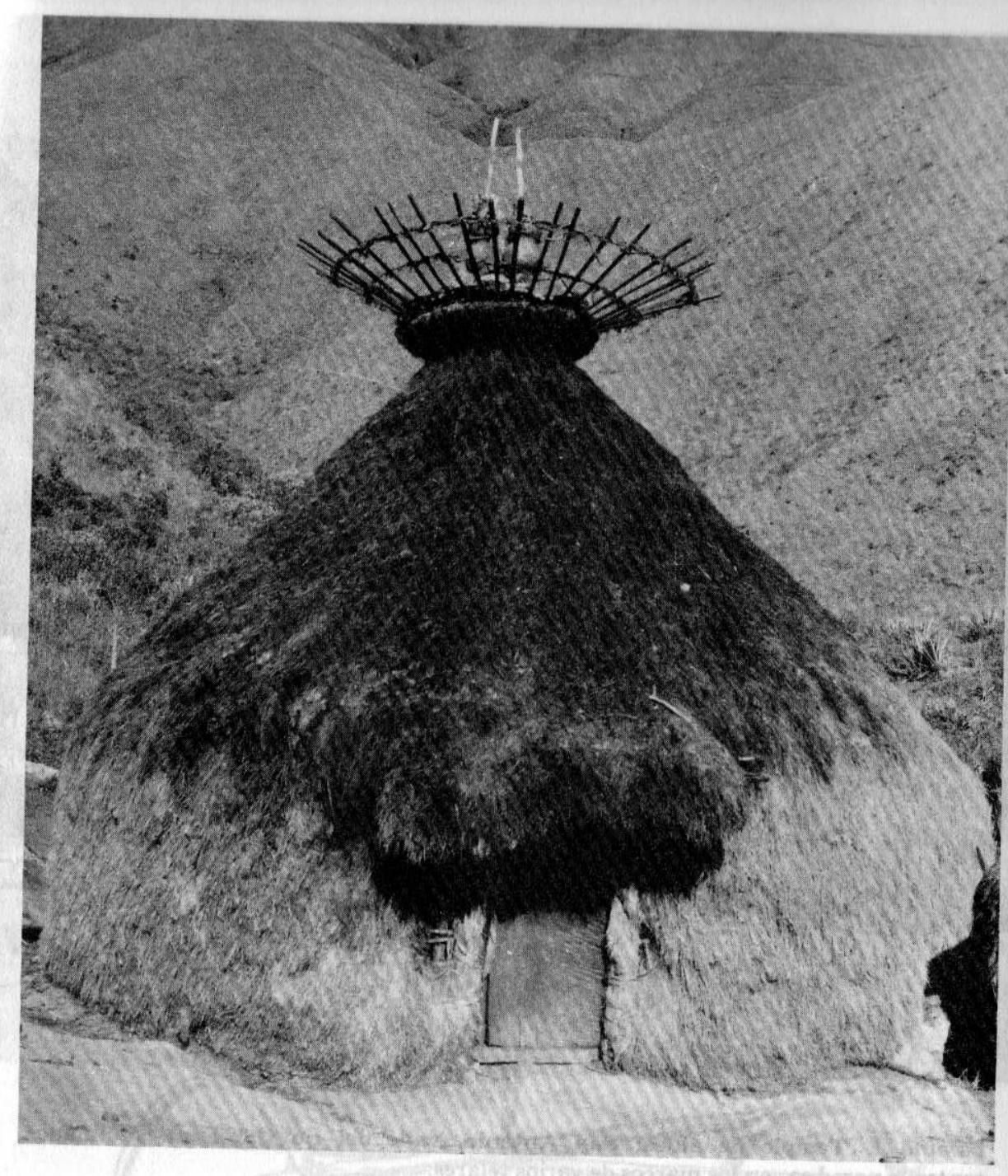

Lámina II. Templo principal 'femenino' de Takina (valle del río San Miguel). Las puertas están orientadas este-oeste.

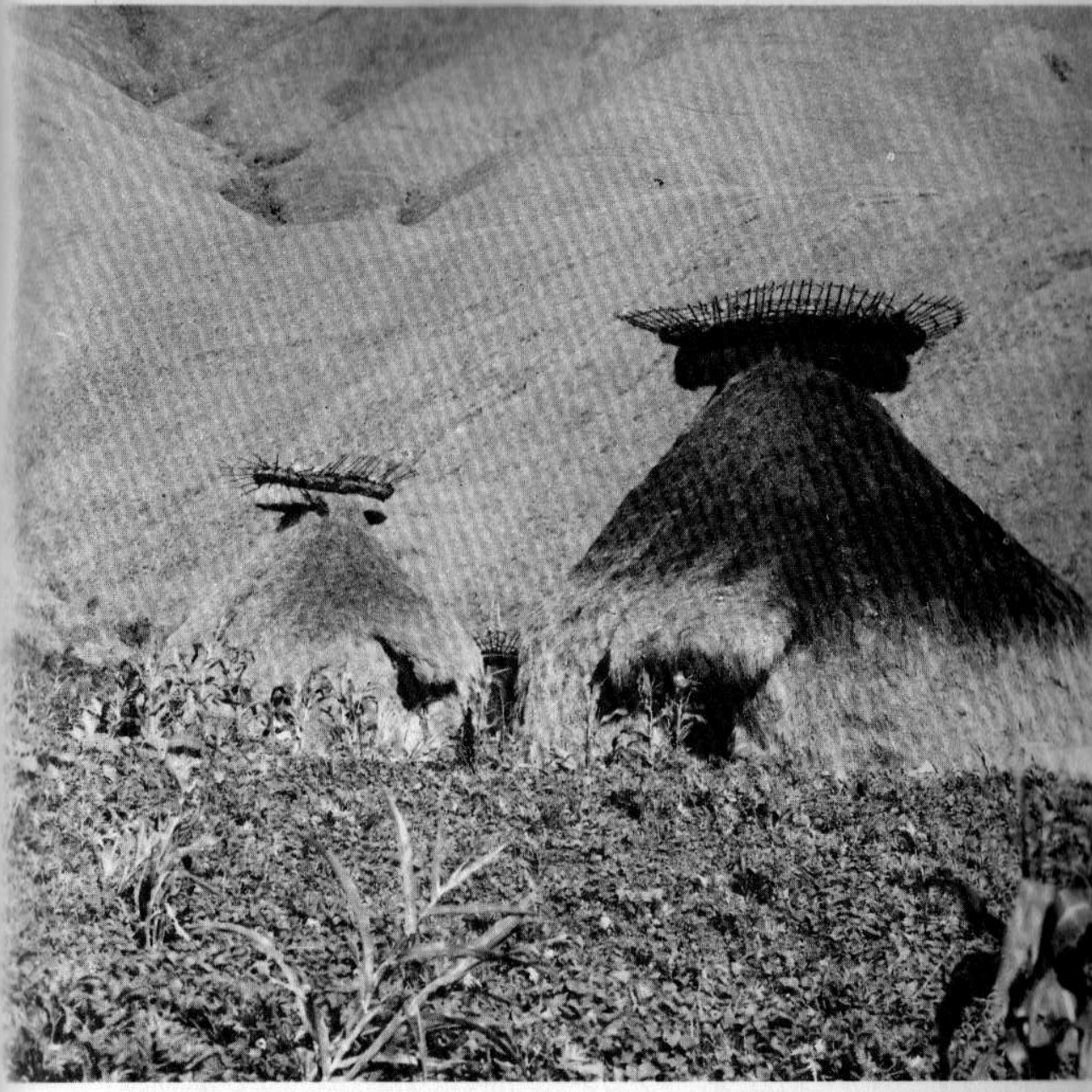

Lámina III. Los templos principales 'masculinos' de Takina. Las puertas del templo a la izquierda están orientadas en dirección este-oeste; las del templo a la derecha, en dirección noroeste-sureste. 